\title{
Detecting de novo mitochondrial mutations in angiosperms with highly divergent evolutionary rates
}

Amanda K. Broz ${ }^{*, 1}$, Gus Waneka ${ }^{*, 1}$, Zhiqiang Wu ${ }^{\dagger, *, 1}$, Matheus Fernandes Gyorfy*, Daniel B. Sloan*,2

*Department of Biology, Colorado State University, Fort Collins, CO 80523

†Shenzhen Branch, Guangdong Laboratory for Lingnan Modern Agriculture, Genome Analysis Laboratory of the Ministry of Agriculture, Agricultural Genomics Institute at Shenzhen, Chinese Academy of Agricultural Sciences, 518120 Shenzhen, China

${ }^{1}$ These authors contributed equally to this work.

${ }^{2}$ Author for Correspondence:

Daniel B. Sloan: dan.sloan@colostate.edu

Colorado State University

1878 Campus Delivery

Fort Collins, CO 80523

970.491 .2256 


\section{ABSTRACT}

3 Although plant mitochondrial genomes typically show low rates of sequence evolution, levels of 4 divergence in certain angiosperm lineages suggest anomalously high mitochondrial mutation rates.

5 However, de novo mutations have never been directly analyzed in such lineages. Recent advances

6 in high-fidelity DNA sequencing technologies have enabled detection of mitochondrial mutations

7 when still present at low heteroplasmic frequencies. To date, these approaches have only been

8 performed on a single plant species (Arabidopsis thaliana). Here, we apply a high-fidelity technique

9 (Duplex Sequencing) to multiple angiosperms from the genus Silene, which exhibits extreme

10 heterogeneity in rates of mitochondrial sequence evolution among close relatives. Consistent with

11 phylogenetic evidence, we found that $S$. latifolia maintains low mitochondrial variant frequencies that

12 are comparable to previous measurements in Arabidopsis. Silene noctiflora also exhibited low

13 variant frequencies despite high levels of historical sequence divergence, which supports other lines

14 of evidence that this species has reverted to lower mitochondrial mutation rates after a past episode

15 of acceleration. In contrast, S. conica showed much higher variant frequencies in mitochondrial (but

16 not in plastid) DNA, consistent with an ongoing bout of elevated mitochondrial mutation rates.

17 Moreover, we found an altered mutational spectrum in S. conica heavily biased towards AT $\rightarrow$ GC

18 transitions. We also observed an unusually low number of mitochondrial genome copies per cell in

19 S. conica, potentially pointing to reduced opportunities for homologous recombination to accurately

20 repair mismatches in this species. Overall, these results suggest that historical fluctuations in

21 mutation rates are driving extreme variation in rates of plant mitochondrial sequence evolution. 


\section{INTRODUCTION}

24 Plant mitochondrial genomes exhibit dramatic variation in rates of nucleotide substitution. Early molecular evolution studies (WOLFE et al. 1987; PALMER AND HERBON 1988) established that mitochondrial rates in most angiosperms are about an order of magnitude lower than in the nucleus (DROUIN et al. 2008), which contrasts with the rapid evolution of mitochondrial DNA (mtDNA) in many other eukaryotic lineages (BRown et al. 1979; SMITH AND KEELING 2015; LAVROV AND PeTt 2016). However, subsequent phylogenetic surveys have identified a number of angiosperms with exceptionally high levels of mtDNA sequence divergence (PALMER et al. 2000; CHO et al. 2004; PARKINSON et al. 2005; MOWER et al. 2007; SLOAN et al. 2009; SKIPPINGTON et al. 2015; ZERVAS et al. 2019). As such, despite the relatively recent origin and diversification of angiosperms (BARBA-

33 MonTOYA et al. 2018), mitochondrial substitution rates are estimated to span a remarkable 5000-fold range across this group (RICHARDSON et al. 2013). At one extreme, Magnolia stellata has a rate of only $\sim 0.01$ synonymous substitutions per site per billion years (SSB), while certain Plantago and Silene species have estimated rates of >50 SSB (MOWER et al. 2007; SLOAN et al. 2012a; RICHARDSON et al. 2013). In some cases, rate accelerations appear to be short-lived with bursts of sequence divergence inferred for internal branches on phylogenetic trees followed by reversions to slower rates of sequence evolution (CHO et al. 2004; PARKINSON et al. 2005; SLOAN et al. 2009; SKIPPINGTON et al. 2017).

The angiosperm genus Silene (Caryophyllaceae) is a particularly interesting model for the study of mitochondrial genome evolution and substitution rate variation. This large genus comprises approximately 850 species (JAFARI et al. 2020) and exhibits rate accelerations that rival the magnitude of other extreme cases in genera such as Plantago, Pelargonium, and Viscum (MowER et al. 2007; SKIPPINGTON et al. 2015). Moreover, Silene is distinct because the observed rate accelerations appear to have occurred very recently (<10 Mya), such that close relatives within the genus exhibit radically different substitution rates (Figure 1) (MOWER et al. 2007; SLOAN et al. 2009; RAUTENBERG et al. 2012). For example, S. latifolia (section Melandrium) has retained a substitution rate that is roughly in line with the low levels of sequence divergence found in most angiosperms. In contrast, species such as S. noctiflora and S. conica represent lineages (sections Elisanthe and Conoimorpha, respectively) that are within the same subgenus as section Melandrium but have highly divergent mtDNA sequence. These large differences among close relatives in Silene have enabled comparative approaches to investigate the evolutionary consequences of accelerated substitution rates for mitochondrial genome architecture (SLOAN et al. 2012a), RNA editing (SLOAN et al. 2010), mitonuclear coevolution (SLOAN et al. 2014; HAVIRD et al. 2015; HAVIRD et al. 2017), and mitochondrial physiology (HAVIRD et al. 2019; WEAVER et al. 2020). Notably, accelerated species such as $S$. noctiflora and $S$. conica also exhibit massively expanded mitochondrial genomes that 
58 have been fragmented into dozens of circularly mapping chromosomes (SLOAN et al. 2012a).

59 However, the mechanisms that cause increased mitochondrial substitution rates in some Silene

60 species remain unclear (HAVIRD et al. 2017).

61 Previous studies on Silene and other angiosperms have generally concluded that elevated

62 rates of mitochondrial sequence evolution reflect increased mutation rates rather than changes in

63 selection pressure (CHO et al. 2004; PARKINSON et al. 2005; MOWER et al. 2007; SLOAN et al. 2009;

64 SLOAN et al. 2012a; SKIPPINGTON et al. 2015). Increases are especially pronounced at synonymous

65 sites, which are thought to experience very limited effects of selection in plant mtDNA (SLOAN AND

66 TAYLOR 2010; WYNN AND CHRISTENSEN 2015). Likewise, the ratio of nonsynonymous to synonymous

67 substitutions $\left(d_{N} / d s\right)$ is still low in accelerated species (SLOAN et al. 2012a), indicating that purifying

68 selection on mitochondrial genes remains strong. In Silene species with rapidly evolving mtDNA,

69 there does not appear to be a genome-wide increase in synonymous substitution rates in the

70 nucleus or plastids (RAUTENBERG et al. 2012; SLOAN et al. 2012b), suggesting that the accelerated

71 point mutation rates are largely specific to the mitochondria. A number of mechanisms have been

72 hypothesized to explain cases of increased mitochondrial mutation rates. However, thus far, all

73 inferences about variation in plant mitochondrial divergence are based on long-term patterns of

74 sequence divergence across species rather than direct detection and analysis of de novo mutations,

75 making it difficult to investigate the actual role of mutation.

Recent advances in high-fidelity DNA sequencing have improved our ability to distinguish

77 signal from noise and detect de novo mutations (SALK et al. 2018; SLOAN et al. 2018). In particular,

78 Duplex Sequencing (SCHMITT et al. 2012; KENNEDY et al. 2014) has been used to obtain error rates

79 as low as $\sim 2 \times 10^{-8}$ per bp, allowing for accurate identification of mitochondrial variants that are still

80 present at low heteroplasmic frequencies within tissue samples (KENNEDY et al. 2013; AHN et al.

81 2016; Hoekstra et al. 2016; ARBeithuBER et al. 2020; Wu et al. 2020a). Duplex Sequencing works

82 by attaching random barcodes to each original DNA fragment and independently sequencing the two

83 complementary DNA strands from that fragment multiple times each to produce a highly accurate

84 double-stranded consensus. To date, Arabidopsis thaliana is the only plant system to have been

85 analyzed with this method (Wu et al. 2020a). Here, we apply Duplex Sequencing to detect de novo

86 mitochondrial and plastid mutations in three Silene species previously inferred to have dramatically

87 different histories of mitochondrial mutation.

$92 \quad$ Plant lines and growth conditions 
93 A single family of full siblings was grown for each of three Silene species. Families were taken from

94 lines with previously sequenced mitochondrial and plastid genomes: S. latifolia UK2600, S. noctiflora

95 OSR, and S. conica ABR (SLOAN et al. 2012a; SLOAN et al. 2012b). The latter two species are

96 hermaphroditic and readily self-fertilize, so families were derived from selfed parents. In contrast, $S$.

97 latifolia is dioecious and exhibits substantial inbreeding depression from full-sib crosses (TEIXEIRA et

98 al. 2009). Therefore, we crossed a female from the UK2600 line with a male from a different line

99 (Kew 32982, obtained from the Kew Gardens Millenium Seed Bank) to produce the full-sib family

100 used in this study. Seeds were germinated on ProMix BX soil mix and grown in a growth room under

101 short-day conditions (10-hr/14-hr light/dark cycle). All three species were grown for approximately

102 seven weeks to produce sufficiently large rosettes for organelle DNA extractions.

103

104 Organelle DNA extractions and Duplex Sequencing

105 Each full-sib family was divided into three biological replicates, consisting of approximately 30-40

106 individual plants per replicate. A total of $35 \mathrm{~g}$ of rosette tissue was harvested from each replicate and

107 used for simultaneous extraction of enriched mtDNA and cpDNA as described previously (Wu et al.

108 2020a; Wu et al. 2020b). Mitochondria were isolated by differential centrifugation followed by DNase

109 I treatment to remove contaminating DNA not protected by intact mitochondrial membranes.

110 Chloroplasts were isolated on discontinuous sucrose gradients. Following DNA extraction, Duplex

111 Sequencing libraries were constructed as described previously (Wu et al. 2020a). These libraries

112 were multiplexed and sequenced with $2 \times 150$ bp reads on an Illumina NovaSeq 6000 S4 Lane

113 (NovoGene).

\section{Shotgun Illumina sequencing of total-cellular DNA samples for $\boldsymbol{k}$-mer database construction}

116 Detection of low-frequency mitochondrial heteroplasmies presents a number of technical challenges

117 that can lead to false positives. In particular, plant nuclear genomes harbor numerous insertions of

118 mtDNA and cpDNA fragments (which are known as "numts" and "nupts", respectively) that can differ

119 in sequence from the mitochondrial or plastid genomes because they accumulate mutations over

120 time (HUANG et al. 2005; Noutsos et al. 2005; LOUGH et al. 2008; HAZKANI-Covo et al. 2010;

121 MichalovovÁ et al. 2013). Therefore, contaminating nuclear DNA in mtDNA and cpDNA samples

122 can mimic low-frequency de novo mitochondrial and plastid mutations. Because numts and nupts

123 often closely resemble the mitochondrial and plastid genome sequence, they can be problematic to

124 accurately assemble in nuclear genome sequencing projects even in high quality reference

125 assemblies (STUPAR et al. 2001). As such, it can be difficult to identify and filter out numt- and nupt-

126 derived variants based only on reference genome assemblies. We have found that an effective

127 alternative is to use raw reads from total-cellular sequencing datasets to generate a database of

128 counts of all sequences of a specified length $k$, which are referred to as $k$-mers (Wu et al. 2020a). 
129 The premise of this approach is that variants associated with numts or nupts should be abundant in

130 total-cellular sequencing datasets (as quantified by counting corresponding $k$-mers in the raw reads)

131 and match the level expected for other nuclear sequences. However, for reasons discussed below

132 (see Results), we expect this filtering approach to be more reliable for numts than for nupts.

133 To generate a $k$-mer database for each species we extracted total-cellular DNA from mature

134 leaf tissue using the Qiagen DNeasy kit. For S. noctiflora and S. conica, the sampled individuals

135 were from the same inbred line as the full-sib family used for Duplex Sequencing but separated by at

136 least three generations. In contrast to the inbred history of the S. noctiflora and S. conica lines, S.

137 latifolia is expected to be highly heterozygous, including for numt and nupt alleles. Therefore, in

138 order to capture all numt and nupt alleles that might be segregating in the S. latifolia full-sib family,

139 we generated total-cellular samples for both parents that were crossed to generate the family.

140 Sampling the male parent in this $S$. latifolia cross also provides reads from its actual mitochondrial

141 genome sequence, which can identify potential false positives resulting from low-frequency paternal

142 transmission of mtDNA. Such "paternal leakage" has been identified in outcrossing Silene species

143 (McCAULey et al. 2005; BENTLEY et al. 2010).

144 Illumina libraries were generated from each total-cellular DNA sample using the New

145 England Biolabs NEB FS II Ultra kit with approximately 100 ng of input DNA, a 20 min fragmentation

146 time, and eight cycles of PCR. The S. latifolia and S. noctiflora libraries were multiplexed and

147 sequenced on the same NovaSeq 6000 lane as the above Duplex Sequencing libraries. The $S$.

148 conica library was sequenced separately with $2 \times 150$ bp reads on an Illumina HiSeq 4000 lane. The

149 resulting raw reads were used to generate databases of $k$-mer counts ( $k=39 \mathrm{bp}$ ) with KMC v3.0.0

150 (KoKOT et al. 2017).

\section{Duplex Sequencing data analysis and variant calling}

153 Duplex Sequencing datasets were processed with a previously published pipeline

154 (https://github.com/dbsloan/duplexseq) (Wu et al. 2020a). This pipeline uses Duplex Sequencing

155 barcodes (i.e., unique molecular identifiers) to group raw reads into families corresponding to the two

156 complementary strands of an original DNA fragment, requiring a minimum of three reads for each

157 strand. After trimming barcodes and linker sequences, the consensus sequences for each double-

158 stranded family were mapped to the reference mitochondrial and plastid genomes for the

159 corresponding species. Because of known sequencing artefacts associated with end repair and

160 adapter ligation (KENNEDY et al. 2014), the $10 \mathrm{bp}$ at the end of each read were excluded when

161 identifying variants and calculating sequencing coverage.

162 Reads that contained a single mismatch relative to the reference sequences were used to

163 identify single nucleotide variants (SNVs). Variants with a $k$-mer count of 10 or greater in the

164 corresponding $k$-mer database were excluded as likely numts or nupts. This $k$-mer filtering also 
165 ensured elimination of false positives due to paternal leakage from the S. latifolia male parent or

166 errors in the published reference sequence. The latter is an important concern because the

167 published S. conica mitochondrial genome sequence is a draft assembly due to its extreme

168 repetitiveness (SLOAN et al. 2012a). Accordingly, we also excluded variants if the corresponding

169 reference sequence was not detected in the $k$-mer database to account for sites with ambiguities

170 (Ns) or possible errors in the reference. Variants were also filtered using the pipeline's

171 --recomb_check option, which identifies SNVs that can be explained by recombination between non-

172 identical repeat sequences within the mitochondrial genome rather than de novo point mutations

173 (DAVILA et al. 2011). Finally, the pipeline's --contam_check option was used to provide the reference

174 genome sequences from the other Silene species for filtering of variants arising from contamination

175 between multiplexed libraries.

176 To calculate SNV frequencies for each library, the number of reads containing an SNV (after

177 filtering) was divided by the total bp of duplex consensus sequence mapped to the genome.

178 Differences in SNV frequency among species were tested with a one-way ANOVA implemented,

179 using the aov function in R v3.6.3 followed by post hoc pairwise comparisons with the TukeyHSD

180 function.

181 For calling mitochondrial SNVs, we were able to use the cpDNA Duplex Sequencing libraries

182 to increase our mitochondrial genome coverage because they contained a substantial amount of

183 contaminating mtDNA reads resulting from incomplete enrichment of cpDNA. Importantly, being able

184 to use mitochondrial reads from the cpDNA library for S. conica biological replicate 2 was key

185 because sequencing of the mtDNA library for that replicate failed (see Results). However, we did not

186 do the reverse (use mtDNA libraries to supplement plastid datasets) because the mtDNA libraries

187 were expected to have a far higher ratio of nuclear to plastid DNA than the cpDNA libraries,

188 exacerbating the challenges associated with filtering nupts.

\section{Analysis of organelle genome copy number}

191 To estimate the copy number of mitochondrial and plastid genomes based on the total-cellular

192 sequencing datasets, raw reads were trimmed with cutadapt v1.16 (MARTIN 2011) to remove adapter

193 sequences with an error tolerance of 0.15 and to trim low-quality ends with a q20 threshold. Read

194 pairs with a minimum length of $50 \mathrm{bp}$ each after trimming were retained. Trimmed reads were then

195 mapped to reference mitochondrial and plastid genomes for the corresponding species using bowtie

196 v2.2.23 (LANGMEAD AND SALZBERG 2012), and position-specific coverage data were extracted from

197 the resulting alignment (BAM/SAM) files. Average coverage was summarized for 2-kb windows tiled

198 across each organelle genome. To estimate the number of mitochondrial and plastid genomes per

199 nuclear genome copy, we assumed that the remaining unmapped reads were all nuclear. We used

200 the total length of these unmapped reads divided by the nuclear genome size of the corresponding 
201 species to estimate the average nuclear genome coverage and obtain ratios of organelle to nuclear

202 coverage. Nuclear genome size estimates of $2.67,2.78$, and $0.93 \mathrm{~Gb}$ were used for S. latifolia, S.

203 noctiflora, and S. conica, respectively (WILLIAMS et al. 2020).

204 The above analysis of genome copy number identified a surprisingly low number of

205 mitochondrial genome copies in S. conica. To validate this unexpected result and compare

206 stoichiometry of mitochondrial, plastid and nuclear genomes across multiple tissue samples in $S$.

207 conica, we performed a droplet digital PCR (ddPCR) analysis. We used the same S. conica total-

208 cellular DNA extraction that was used for the Illumina shotgun sequencing. In addition, we harvested

209 leaf tissue from three individuals from a different batch of $S$. conica ABR plants. For both the original

210 sample and the newer samples, tissue was harvested from the largest rosette leaves. The original

211 sample was grown in a growth chamber under long-day conditions (16-hr/8-hr light/dark cycle) and

212 harvested after 28 days, whereas the newer samples were grown on light racks in a growth room

213 under short-day conditions (10-hr/14-hr light/dark cycle) and harvested after 40 days. The tissue

214 sampling also differed in that the entire rosette leaf was sampled for the newer replicates, whereas

215 only the distal half of the leaf was taken for the original DNA extraction. In both cases, DNA

216 extractions were performed with a Qiagen DNeasy Kit. A total of six ddPCR markers were

217 developed, with two each targeting the mitochondrial, plastid and, nuclear genomes (Table S1).

218 Each ddPCR reaction was set up in a $20 \mu$ volume, containing Bio-Rad QX200 ddPCR EvaGreen

219 Supermix and $0.2 \mu \mathrm{M}$ of each primer. For mitochondrial and nuclear markers, $5 \mathrm{ng}$ of total-cellular

220 DNA was used as template. To avoid saturation with the higher-copy-number plastid makers, a 200-

221 fold dilution (25 pg) of the template DNA was used. The reaction volumes were then emulsified in

222 Bio-Rad QX200 Droplet Generation Oil for EvaGreen, using the Bio-Rad QX200 Droplet Generator.

223 PCR amplification was performed on a Bio-Rad C1000 Touch thermal cycler with an initial

224 incubation at $95^{\circ} \mathrm{C}$ for $5 \mathrm{~min}, 40$ cycles of $90^{\circ} \mathrm{C}$ for $30 \mathrm{~s}$ and $60^{\circ} \mathrm{C}$ for $1 \mathrm{~min}$, followed by a $4{ }^{\circ} \mathrm{C}$

225 incubation for $5 \mathrm{~min}$ and a final $90^{\circ} \mathrm{C}$ incubation for $5 \mathrm{~min}$ before holding at $4{ }^{\circ} \mathrm{C}$. After amplification,

226 droplets were analyzed on a Bio-Rad QX200 Droplet Reader, and the absolute copy number of each

227 PCR target was estimated based on a Poisson distribution in the Bio-Rad QuantaSoft package.

228 Mitochondrial:nuclear and plastid:nuclear ratios were calculated by dividing organellar marker copy

229 numbers by the mean of the estimates for the two nuclear markers for a given sample.

\section{Data Availability}

232 All duplex sequencing and shotgun Illumina sequencing reads were deposited to the NCBI

233 Sequence Read Archive (SRA) under BioProject PRJNA682809 (Table S2). 


\section{RESULTS}

\section{Duplex Sequencing yield and read mapping}

239 Each of the Duplex Sequencing libraries produced between $88 \mathrm{M}$ and $142 \mathrm{M}$ read pairs (Table S2),

240 with the exception of the $S$. conica mtDNA library for biological replicate 2, which was not sequenced

241 due to an apparent loading error. Nevertheless, we were still able to calculate mitochondrial SNV

242 frequencies for $S$. conica replicate 2 by taking advantage of contaminating mitochondrial reads in the

243 enriched cpDNA library for that replicate. The large number of reads per library translated into

244 sizeable single-stranded read families for construction double-stranded consensus sequences, with

245 modal values of $>10$ reads per family for most libraries (Figure S1). The three species differed in

246 their degree of enrichment in the mtDNA libraries. For both S. noctiflora and S. conica, an average of

$24779 \%$ of the sequences in the mtDNA libraries could be mapped to the reference mitochondrial

248 genome, whereas only $30 \%$ of the sequences in the S. latifolia mitochondrial libraries mapped,

249 indicating a much lower level of mtDNA enrichment (Table S2). For all three species, between 64\%

250 and $67 \%$ of sequences from the cpDNA libraries mapped to the plastid genome, with a substantial

251 number of contaminating sequences mapping to the mitochondrial genome $(8 \%, 27 \%$, and $31 \%$ for

252 S. latifolia, S. noctiflora, and S. conica, respectively). To make use of as much mitochondrial data as

253 possible, we combined all mitochondrial-derived sequences from both sample types. After collapsing

254 raw reads into duplex consensus sequences and mapping them to the reference genome, we

255 obtained between 85 and $382 \mathrm{Mb}$ of mapped mitochondrial sequence data for each replicate (based

256 on combing coverage from both mtDNA and cpDNA libraries; Table S2). For plastid genome

257 coverage, we relied solely on the cpDNA libraries, which yielded between 203 and $319 \mathrm{Mb}$ of

258 coverage per replicate (Table S2).

Three Silene species differ in their frequencies of mitochondrial SNVs but show little

262 Using the variant calls from the duplex consensus sequences (File S1), we calculated the frequency

263 of mitochondrial SNVs per mapped bp for each Silene replicate and compared those values to

264 previously published estimates from A. thaliana (WU et al. 2020a). After applying filtering criteria to

265 exclude false positives associated with numts, low-frequency paternal transmission, chimeric

266 recombination products, or errors in the reference sequence (see Materials and Methods), we found

267 significant variation in (log-transformed) mitochondrial SNV frequency among species (one-way

268 ANOVA, $p=5.3 \times 10^{-6}$; Figure 2, Table S3).

269 The three biological replicates of S. latifolia had a mean mitochondrial SNV frequency of 1.7

$270 \times 10^{-7}$ per bp. Silene latifolia was selected for this study because it exhibited very little mitochondrial 
rate acceleration in previous phylogenetic analyses, suggesting that it has retained the slow rate of sequence evolution that is characteristic of most plant mitochondrial genomes (MOWER et al. 2007; SLOAN et al. 2009). Accordingly, the S. latifolia estimate was very similar to our previous estimate of $1.8 \times 10^{-7}$ per bp for the mitochondrial SNV frequency in wild type A. thaliana Col-0 (WU et al. 2020a), another plant species with a typically low rate of mitochondrial sequence evolution (MOWER et al. 2007). In contrast to the low historical substitution rates in S. latifolia and Arabidopsis, S. noctiflora exhibits highly accelerated mitochondrial sequence evolution since diverging from other major lineages within the genus Silene (Figure 1). However, we did not find an elevated frequency of mitochondrial SNVs in our Duplex Sequencing analysis of S. noctiflora, suggesting that this species may have experienced a reversion to lower mutation rates. In fact, the mean SNV frequency in $S$. noctiflora was $6.1 \times 10^{-8}$ per bp, which was approximately 3 -fold lower than in S. latifolia or $A$. thaliana (Tukey's HSD post hoc test, $p=0.01$ for both comparisons). The most noteworthy variation among species was based on observed SNV frequencies in S. conica, representing another Silene lineage with a history of rapid mitochondrial sequence divergence (Figure 1). The mean mitochondrial SNV frequency in S. conica was $1.7 \times 10^{-6}$ per bp, which was 9-fold to 27 -fold higher than in A. thaliana and the other two Silene species (Tukey's HSD post hoc test, $p<0.0001$ for all three comparisons). All of these SNV frequencies substantially exceed the noise threshold of $\sim 2 \times$ $10^{-8}$ that we previously estimated for this protocol using Escherichia coli samples derived from single colonies as "negative controls" (Wu et al. 2020a).

Silene conica was also distinct in that a large proportion of the identified mitochondrial SNVs $(31.7 \%)$ were found in two or more biological replicates. Because our biological replicates represented sets of individuals from the same full-sib family, variants that are shared among replicates likely indicate SNVs that were already heteroplasmic in the parent and then inherited by the offspring. In contrast, none of the identified mitochondrial SNVs in either S. latifolia or $S$. noctiflora were present in multiple biological replicates. There is reason to expect that our $k$-mer filtering may have introduced bias against detection of inherited heteroplasmies in S. latifolia (see Discussion). Nevertheless, even without this filtering, only $3.7 \%$ of $S$. latifolia SNVs (and only $1.8 \%$ of S. noctiflora SNVs) would be present in two or more libraries. Therefore, the filtering does not appear to explain this observed difference between S. conica and the other Silene species.

Unlike in the mitochondrial genome, we found no evidence that $S$. conica has an elevated

302 plastid SNV frequencies (Figure 2). We recommend that the estimates of the Silene plastid SNV

303 frequencies and spectra be interpreted cautiously because of the nuclear contamination in these 304 libraries and the fact that nupts are more difficult to reliably filter with our $k$-mer database than 305 numts. The challenge that nupts pose relates to the high coverage of true plastid DNA in our total- 
cellular libraries $(>10,000 \times)$. As such, even rare sequencing errors in total-cellular libraries have the potential to occur repeatedly and exhibit sizeable counts in our $k$-mer database, which could lead to exclusion of variant calls that are actually true de novo mutations. Nevertheless, we can confidently conclude that $S$. conica does not exhibit a major increase in plastid SNV frequency. Even if we performed no $k$-mer filtering whatsoever on the S. conica plastid samples, SNV frequencies would

311 only increase by $55 \%$ on average (Table S4), leaving them at a level that is still similar to that of the 312 other Silene species and more than an order of magnitude lower than the (filtered) mitochondrial

313 SNV frequencies in S. conica (Figure 2).

Variation in mitochondrial mutation spectra among Silene species and extreme GC bias in S. conica

317 Previous analysis of low-frequency mitochondrial SNVs in rosette tissue from wild type $A$. thaliana

318 Col-0 (Wu et al. 2020a) identified a mutation spectrum dominated by GC $\rightarrow$ AT transitions (Figure 2).

319 The slowly evolving S. latifolia mitochondrial genome exhibited a bias in this same direction with

$32057 \%$ of all observed SNVs being GC $\rightarrow$ AT transitions (Table S3). In contrast, S. noctiflora did not

321 show a similar bias. The low overall SNV frequency in S. noctiflora makes it difficult to precisely

322 estimate the mutation spectrum, but no single substitution type dominated, as GC $\rightarrow$ AT transitions,

323 AT $\rightarrow$ GC transitions, and $G C \rightarrow C G$ transversions all had similar frequencies in the observed set of

324 SNVs (Figure S2, Table S3). Once again, S. conica exhibited the most extreme departure from the

325 other species. Notably, the high rate in S. conica was not driven by an increased frequency of the

$326 \mathrm{GC} \rightarrow$ AT transitions that dominate the spectrum of $A$. thaliana and $S$. latifolia. In fact, the frequency

327 of GC $\rightarrow$ AT transitions in S. conica was lower than in either of those species. Instead, the high

328 overall SNV frequency was largely the result of a massive increase in the frequency AT $\rightarrow G C$

329 transitions, which account for $77 \%$ of the observed SNVs in S. conica (Figure 2; Table S3). This

330 species also exhibited a substantial increase in the frequency of AT $\rightarrow$ CG transversions (11\% of

331 observed SNVs). As such, both of the dominant types of substitutions in the S. conica mitochondrial

332 mutation spectrum increase GC content, which is unusual because mutation spectra are generally

333 AT-biased (Hershberg and Petrov 2010; HiLdebrand et al. 2010; SloAn ANd Wu 2014).

\section{Unusually low mitochondrial genome copy number in Silene conica rosette tissue}

336 By performing deep sequencing of total-cellular DNA to generate a $k$-mer database for variant

337 filtering, we were also able to estimate the relative copy number of mitochondrial, plastid, and

338 nuclear genomes in each of the three Silene species (Figures 3 and S3-S5, Table S5). We found

339 similar plastid genome copy numbers across species, with mean estimates of 378, 263, and 275

340 plastid genome copies per nuclear genome copy for S. latifolia, S. noctiflora, and S. conica,

341 respectively. If we assume that each cell is diploid and has not yet undergone DNA replication, the 
342 plastid genome copy numbers per cell would be double those values, but that may be an

343 underestimate because many plants undergo extensive endoreduplication, in which the nuclear

344 genome replicates without subsequent cell divisions, resulting in cells with higher nuclear ploidies

345 (JOUBES AND CHEVALIER 2000). The number of mitochondrial genome copies was surprisingly low in

346 S. conica, with an average of only 0.38 copies per nuclear genome copy. In contrast, S. latifolia and

347 S. noctiflora had an average of 47.7 and 9.7 mitochondrial genome copies per nuclear genome

348 copy, respectively, which is more consistent with estimates from other plants (PREUTEN et al. 2010;

349 OldenBurg et al. 2013; SHEN et al. 2019).

350 To validate the finding of extremely low mitochondrial genome copy number in S. conica, we 351 performed a ddPCR analysis with two markers each for the mitochondrial, plastid, and nuclear

352 genomes. We first analyzed DNA from the same extraction that was originally used for the total-

353 cellular Illumina shotgun sequencing, obtaining an estimate of 0.42 mitochondrial genomes per

354 nuclear genome, in close agreement with our estimate of 0.38 from the sequencing data. Based on

355 this ddPCR analysis, we also estimated that there were 737 copies of the plastid genome per

356 nuclear genome copy, which was 2.7-fold higher than our original estimate (Figure 3), possibly

357 indicating that our sequencing estimate was downwardly biased for plastid genome copy number.

358 We then analyzed leaf DNA collected from three new S. conica plants that were grown separately

359 from the originally sampled plant to assess whether the original DNA extraction was anomalous in

360 some way. These three new samples also produced extremely low estimates for the number of

361 mitochondrial genomes copies with a mean of 1.02 per nuclear genome copy (Figure 3 and Table

362 S6). Therefore, these new S. conica samples exhibited a small increase in the mitochondrial:nuclear

363 ratio relative to our original sample but still fell well below typical observations for plant cells.

\section{DISCUSSION}

\section{The challenges of detecting de novo mutations in plant organelle genomes}

369 High-fidelity techniques such as Duplex Sequencing (SCHMITT et al. 2012) have been key

370 innovations to address the challenge of detecting and quantifying rare mutations (SALK et al. 2018;

371 SLOAN et al. 2018), but some sources of false positives remain. The potential misidentification of

372 numts and nupts as de novo mutations was a particular concern in this study. High quality nuclear

373 genome assemblies are not available for Silene, so it is not possible to use a reference genome to

374 identify and filter numt- and nupt-associated variants. Moreover, our mitochondrial and plastid DNA

375 preparations only reached moderate levels of enrichment, leaving substantial amounts of

376 contaminating nuclear DNA (Table S2). Our approach to avoid erroneous numt and nupt variant

377 calls was based on filtering using a $k$-mer database derived from total-cellular sequencing (see 
Materials and Methods), but there are some concerns about balancing false positives and false negatives that should be considered.

In particular, there is a risk that $k$-mer filtering may exclude true heteroplasmies if they are shared between the total-cellular sample used to generate the $k$-mer database and the family used for Duplex Sequencing. We reduced the risk of this in S. conica and S. noctiflora by using individuals separated by at least three generations for constructing the $k$-mer database. Therefore, lowfrequency heteroplasmies would have to have been maintained across multiple generations to lead to improper exclusion of true mitochondrial variants. Although transmission of heteroplasmies across generations certainly occurs (MCCAULEY 2013; ZHANG et al. 2018; MANDEL et al. 2020), the segregational loss of low-frequency variants should greatly reduce the magnitude of this problem. In contrast, for the outcrossing species S. latifolia, we used both parents of the full-sib family to construct total-cellular $k$-mer databases in order to screen for possible numts and nupts in all contributing nuclear haplotypes. As such, variants that were heteroplasmic in the S. latifolia mother and transmitted to her offspring might have been improperly filtered because of their presence in the total-cellular $k$-mer database, resulting in a potential downward bias on our estimate of the overall frequency of SNVs in S. latifolia.

Despite the uncertainty that this introduces into SNV frequency estimates, we feel that the major qualitative conclusions of this study are robust to the challenges of numt and nupt artefacts. For example, the finding that $S$. noctiflora appears to have "reverted" to a low SNV frequency is not sensitive to $k$-mer filtering. Even if no $k$-mer filtering whatsoever were performed for $S$. noctiflora, it would still exhibit an SNV frequency lower than the filtered values from the other three species (Table S3). Likewise, even if we did not perform any numt filtering on the S. latifolia SNVs (which would almost certainly lead to a substantial overestimation of true mitochondrial mutations), the SNV frequency for $S$. latifolia would still not reach the highly elevated levels in S. conica. Therefore, the key distinctions among the three species in mitochondrial SNV frequency appear to hold even though some caution is warranted in interpreting the specific frequency estimate in S. latifolia. Furthermore, as noted in the Results, the conclusion that plastid SNV frequencies remain low in S. conica is not sensitive to $k$-mer filtering, as removing this filtering step only produces a modest

410 The high frequency of mitochondrial SNVs captured by Duplex Sequencing in S. conica tissue

411 (Figure 2) is consistent with previous interpretations that increased mutation rates are driving 412 accelerated mitochondrial genome evolution in this and other atypical plant species (CHO et al. 2004; 413 PARKINSON et al. 2005; MOWER et al. 2007; SLOAN et al. 2009; SLOAN et al. 2012a; SKIPPINGTON et 
414 al. 2015). This view has become the consensus because accelerations are evident at relatively

415 neutral positions like synonymous sites over phylogenetic timescales, but de novo mitochondrial

416 mutations have never been directly investigated in these high-rate plant lineages until now. The

417 huge increase in AT $\rightarrow$ GC transitions that dominated the $S$. conica mutation spectrum (Figure 2)

418 coincides with the most common type of misincorporation observed in steady-state kinetic analysis

419 of the Arabidopsis mitochondrial DNA polymerases, which appear to be prone to misincorporating

420 Gs opposite Ts (AYALA-GARCíA et al. 2018). Therefore, it is possible that the increased mitochondrial

421 substitution rate and biased mutation spectrum in $S$. conica reflect a reduced ability to repair

422 mismatches created by polymerase misincorporations. A disproportionate increase in AT $\rightarrow G C$

423 transitions was also observed in Arabidopsis mutants lacking a functional copy of MSH1 (Wu et al.

424 2020a), a gene that may be involved in repair of mismatches via homologous recombination

425 (CHRISTENSEN 2014; WYNN et al. 2020). An intact and transcribed copy of MSH1 is retained in S.

426 conica (HAVIRD et al. 2017), but its function and expression patterns have not been investigated.

427 Alternatively, GC-biased gene conversion has also been hypothesized as a mechanism to explain

428 skewed substitution patterns in some plant mitochondrial genomes (LIU et al. 2020).

429 The extreme bias towards AT $\rightarrow$ GC transitions in S. conica mitochondrial SNVs (Figure 2) is

430 not entirely consistent with longer-term patterns of mitochondrial sequence divergence in this

431 species. The genome-wide GC content in S. conica (43.1\%) is only slightly higher than in congeners

432 like S. latifolia (42.6\%), S. noctiflora (40.8\%), and S. vulgaris (41.8\%) (SLOAN et al. 2012a). An

433 analysis that used plastid DNA insertions in mitochondrial genomes as neutral markers did find that

434 S. conica had unusually high transition:transversion ratio compared to other angiosperms (SLOAN

435 AND WU 2014), which is consistent with the Duplex Sequencing results. However, it did not detect

436 the strong GC bias that we observed in the current study.

$437 \quad$ These discrepancies between phylogenetic patterns and our duplex sequencing data raise

438 two obvious possibilities. First, the observed SNVs in this study may not reflect the spectrum of

439 heritable mutations because they are measured from rosette tissue and thus are expected to include

440 some de novo mutations that occurred in vegetative tissues and were not inherited from the mother

441 or transmitted to future generations. Our choice to sample whole rosettes (as opposed to more

442 targeted "germline" tissue such as dissected meristems) reflected the practical need to obtain

443 sufficient quantities of mtDNA and cpDNA for Duplex Sequencing library construction. Although it is

444 important to recognize the observed SNVs include some mutations that are not heritable, we do not

445 believe that this is likely to be the primary explanation for inferred differences in mitochondrial

446 mutation spectra. A large proportion of the S. conica SNVs were shared across more than one

447 biological replicate, implying that they were inherited from a heteroplasmic mother and thus

448 transmitted across generations. Furthermore, these shared variants were even more skewed

449 towards AT $\rightarrow$ GC transitions than variants that were only detected in a single replicate (Table S7), 
450 suggesting that heritable mutations do indeed exhibit a very strong GC bias. Relatedly, the fact that

451 S. conica had such a large number of shared SNVs compared to the other two Silene species (see

452 Results and Table S7) supports the conclusion that the higher overall SNV frequency in S. conica is 453 not solely due to a higher mutation rate in vegetative tissue and indeed reflects an elevated rate of 454 heritable mutations.

455 Second, it is possible that the mitochondrial mutation spectrum in S. conica is unstable and 456 has changed over time such that the "snapshot" from Duplex Sequencing of heteroplasmic SNVs 457 does not match the average spectrum over the past millions of years in this lineage. A recent 458 analysis of another genus with accelerated mitochondrial sequence divergence (Ajuga) found large 459 increases in GC content (LIU et al. 2020), suggesting that bouts of accelerated and GC-biased 460 evolution can occur in angiosperm mitochondrial genomes.

461 In contrast to the findings in S. conica, we did not observe elevated SNV frequencies in S.

462 noctiflora (Figure 2) despite a comparable history of accelerated sequence evolution (Figure 1). The 463 low SNV frequencies in S. noctiflora suggest that it has reverted to lower mutation rates after a past 464 episode of acceleration. This type of reversion has been inferred based on phylogenetic evidence in 465 other accelerated lineages such as Plantago and Pelargonium (CHO et al. 2004; PARKINSON et al. 466 2005). We also have previously speculated that $S$. noctiflora no longer has a high mitochondrial 467 mutation rate based on its reduced rate of sequence divergence from close relatives $S$. turkestanica 468 and $S$. undulata and its extremely low amount of intraspecific sequence polymorphism (SLOAN et al. 469 2009; SLOAN et al. 2012a; Wu et al. 2015; WU AND SLOAN 2019). However, if a mutation rate 470 reversion has occurred in this lineage, it may not have simply reversed the process that led to the 471 initial rate increase. Notably, S. noctiflora had a different mitochondrial mutation spectrum than the 472 two species that have maintained low mitochondrial substitution rates throughout their histories $(A$. 473 thaliana and S. latifolia). It also retains a mitochondrial genome that is radically altered in size, 474 structure, and apparent recombinational activity (SLOAN et al. 2012a). Therefore, the mechanisms 475 responsible for mitochondrial DNA replication and maintenance in $S$. noctiflora may still be quite 476 different than in typical angiosperms despite the apparent reversion to ancestral-like rates in this 477 species.

$478 \quad$ The above interpretations are largely based on the premise that the abundance of 479 heteroplasmic SNVs is correlated with the mutation rate. Although it is probably a reasonable 480 assumption that these two features are correlated, the amount of heteroplasmic genetic variation 481 that is maintained will also depend on the (effective) population size of mitochondrial genome 482 copies. Therefore, we cannot rule out the possibility that some of the observed differences in SNV 483 frequency among species could be related to variation in traits such as the extent of the mtDNA 484 transmission bottleneck during reproduction (STEWART AND CHINNERY 2015; ZHANG et al. 2018; 485 JOHNSTON 2019). Likewise, analysis of mitochondrial SNVs in Arabidopsis leaf tissue has indicated 
486 that variant frequencies may be affected by features such as plant age and development (WYNN et

487 al. 2020). Therefore, future studies to separate effects of mutation and population size will be useful.

488 One possibility is that heteroplasmic SNVs identified by Duplex Sequencing could then be tracked

489 across generations with allele-specific ddPCR. Quantifying variance in levels of inherited

490 heteroplasmies can serve as an effective means to quantify the effective number of transmitted

491 genome copies (JOHNSTON 2019). However, this may be more challenging with species such as $S$.

492 latifolia and S. noctiflora where inherited heteroplasmies appear to be rare.

\section{Mitochondrial genome copy number and recombinational repair}

495 One unexpected finding from total-cellular shotgun sequencing was the remarkably low copy number

496 of the mitochondrial genome is S. conica (Figure 3). The ratio of mitochondrial to nuclear genome

497 copies in the analyzed leaf tissue samples implies that there is only about one to two mitochondrial

498 genome copies per cell, under the assumption that most cells are diploid. However, this would

499 depend on the extent of endoreduplication in S. conica. Species with smaller nuclear genomes have

500 been found to undergo a greater amount of endoreduplication on average (BAROW AND MEISTER

501 2003), so it is possible that the ratio of organellar to nuclear genome copies is skewed downward in

502 S. conica for this reason. Although there is evidence that plant cells can have far more mitochondria

503 than mitochondrial genome copies (PREUTEN et al. 2010; SHEN et al. 2019), it is difficult to imagine

504 how mitochondrial function could be maintained throughout development with only one or two

505 mitochondrial genome copies per cell. The sequencing and ddPCR datasets used to generate copy-

506 number estimates were derived from mature rosette leaf tissue. Therefore, it is possible that this is a

507 case of mitochondrial genome "abandonment" in tissue that is not destined for further growth or

508 reproduction (BENDICH 2013; OLdENBURG et al. 2013; WYNN et al. 2020). Previous studies have

509 suggested that some plants undergo a major decline in plastid genome copy number in mature

510 leaves (SHAVER et al. 2006; ROWAN et al. 2009), although this conclusion has been the subject to

511 substantial criticism and debate (GoLCZYK et al. 2014; GREINER et al. 2020). We found that all three

512 Silene species retained hundreds of plastid genome copies per cell, but the dramatic differences in

513 mitochondrial genome copy number across species have intriguing implications. An important future

514 direction will be to characterize variation in S. conica mitochondrial genome copy numbers

515 throughout development, especially in meristematic and reproductive tissues.

$516 \quad$ Even under the likely scenario that other $S$. conica tissues harbor higher mitochondrial

517 genome copy numbers than observed in our analysis, it is possible that such values will still be

518 unusually low compared to most plants and other eukaryotes. Silene conica is distinct in having one

519 of the largest and most fragmented mitochondrial genomes ever identified (SLOAN et al. 2012a).

520 Such genome size and architecture might pose a challenge for mtDNA maintenance in this species.

521 Notably, mtDNA accounted for a similar proportion of total-cellular DNA in S. conica and S. latifolia 
522 despite the $\sim 100$-fold difference in mitochondrial genome copy number between these samples

523 because the $S$. conica mitochondrial genome is $\sim 45$-fold larger than in S. latifolia, and the S. conica

524 nuclear genome is $\sim 3$-fold smaller than in S. latifolia. Nevertheless, the low mitochondrial genome

525 copy number in $S$. conica means that any given region of the mitochondrial genome, including key

526 functional content such as protein-coding sequence, has an unusually low stoichiometry relative to

527 the nucleus.

528 We hypothesize that low mitochondrial genome copy number may be a cause of the high

529 mutation rates in S. conica. It is thought that the typically low mutation rates in plant organelle

530 genomes can be attributed to accurate DNA repair via homologous recombination (KHAKHLOVA AND

531 Bock 2006; Christensen 2014; AyAlA-García et al. 2018; CheVIGnY et al. 2020; Wu et al. 2020a).

532 As such, the ability to maintain low rates would be sensitive to the availability of templates for

533 recombinational repair and, thus, the number of genome copies. Notably, we did not observe

534 elevated SNV frequencies in the S. conica plastid genome (Figure 2), which appears to retain a

535 typical copy number, unlike the $S$. conica mitochondrial genome (Figure 3). This hypothesized role of

536 copy number in recombinational repair is consistent with the observation that nucleotide substitution

537 rates are lower in large repeats than in single-copy regions within plant organelle genomes (WOLFE

538 et al. 1987; DAVILA et al. 2011; ZHU et al. 2016). Therefore, if the population of mitochondrial genome

539 copies is too sparsely distributed in the cells of $S$. conica, it may be unable to make full use of

540 recombinational repair and instead rely on less accurate forms of repair or leave some DNA damage

541 and mismatches entirely unrepaired. In dissertation research conducted with Jeffrey Mower, Wenhu

542 Guo (2014) arrived at a similar hypothesis after observing an unusually low mitochondrial genome

543 copy number in Plantago media, another angiosperm with extremely elevated rates of mitochondrial

544 sequence evolution ( $\mathrm{CHO}$ et al. 2004). Therefore, it appears possible that correlated changes in

545 mitochondrial mutation rate and genome copy number may have occurred many times

546 independently in plants. Testing this hypothesized relationship between mitochondrial genome copy

547 number and mutation rate should provide insight into the causes of extreme variation in rates of

548 mitochondrial sequence evolution observed across angiosperms.

551 ACKNOWLEDGEMENTS

553 We thank Justin Havird for helpful discussion and providing S. conica full-sib seeds and Jessica

554 Warren for assistance with DNA extraction and figure preparation. We also thank two anonymous

555 reviewers for insightful comments that improved the manuscript. This work was supported by a grant

556 from the NIH (R01 GM118046) and an NSF graduate fellowship (DGE-1450032). 


\section{REFERENCES}

Ahn, E. H., S. H. Lee, J. Y. Kim, C.-C. Chang and L. A. Loeb, 2016 Decreased mitochondrial mutagenesis during transformation of human breast stem cells into tumorigenic cells. Cancer Research 76: 4569-4578.

Arbeithuber, B., J. Hester, M. A. Cremona, N. Stoler, A. Zaidi et al., 2020 Age-related accumulation of de novo mitochondrial mutations in mammalian oocytes and somatic tissues. PLoS Biology 18: e3000745.

Ayala-García, V. M., N. Baruch-Torres, P. L. García-Medel and L. G. Brieba, 2018 Plant organellar DNA polymerases paralogs exhibit dissimilar nucleotide incorporation fidelity. The FEBS Journal 285: 4005-4018.

Barba-Montoya, J., M. dos Reis, H. Schneider, P. C. Donoghue and Z. Yang, 2018 Constraining uncertainty in the timescale of angiosperm evolution and the veracity of a Cretaceous Terrestrial Revolution. New Phytologist 218: 819-834.

Barow, M., and A. Meister, 2003 Endopolyploidy in seed plants is differently correlated to systematics, organ, life strategy and genome size. Plant, Cell \& Environment 26: 571-584.

Bendich, A. J., 2013 DNA abandonment and the mechanisms of uniparental inheritance of mitochondria and chloroplasts. Chromosome Research 21: 287-296.

Bentley, K. E., J. R. Mandel and D. E. McCauley, 2010 Paternal leakage and heteroplasmy of mitochondrial genomes in Silene vulgaris: evidence from experimental crosses. Genetics 185: 961-968.

Brown, W. M., M. George and A. C. Wilson, 1979 Rapid evolution of animal mitochondrial DNA. Proceedings of the National Academy of Sciences 76: 1967-1971.

Chevigny, N., D. Schatz-Daas, F. Lotfi and J. M. Gualberto, 2020 DNA repair and the stability of the plant mitochondrial genome. International Journal of Molecular Sciences 21: 328.

Cho, Y., J. P. Mower, Y. L. Quu and J. D. Palmer, 2004 Mitochondrial substitution rates are extraordinarily elevated and variable in a genus of flowering plants. Proceedings of the National Academy of Sciences of the United States of America 101: 17741-17746.

Christensen, A. C., 2014 Genes and junk in plant mitochondria-repair mechanisms and selection. Genome Biology and Evolution 6: 1448-1453.

Davila, J. I., M. P. Arrieta-Montiel, Y. Wamboldt, J. Cao, J. Hagmann et al., 2011 Double-strand break repair processes drive evolution of the mitochondrial genome in Arabidopsis. BMC Biology 9: 64.

Drouin, G., H. Daoud and J. Xia, 2008 Relative rates of synonymous substitutions in the mitochondrial, chloroplast and nuclear genomes of seed plants. Molecular Phylogenetics and Evolution 49: 827-831.

Golczyk, H., S. Greiner, G. Wanner, A. Weihe, R. Bock et al., 2014 Chloroplast DNA in mature and senescing leaves: a reappraisal. Plant Cell 26: 847-854.

Greiner, S., H. Golczyk, I. Malinova, T. Pellizzer, R. Bock et al., 2020 Chloroplast nucleoids are highly dynamic in ploidy, number, and structure during angiosperm leaf development. The Plant Journal 102: 730-746.

Guo, W., 2014 Evolution of organellar genome architecture in seed plants: The role of intracellular gene transfer, recombination and mutation, pp. 107-144. University of Nebraska, Lincoln, Nebraska.

Havird, J. C., G. R. Noe, L. Link, A. Torres, D. C. Logan et al., 2019 Do angiosperms with highly divergent mitochondrial genomes have altered mitochondrial function? Mitochondrion 49: 111.

Havird, J. C., P. Trapp, C. Miller, I. Bazos and D. B. Sloan, 2017 Causes and consequences of rapidly evolving mtDNA in a plant lineage. Genome Biology and Evolution 9: 323-336.

Havird, J. C., N. S. Whitehill, C. D. Snow and D. B. Sloan, 2015 Conservative and compensatory evolution in oxidative phosphorylation complexes of angiosperms with highly divergent rates of mitochondrial genome evolution. Evolution 69: 3069-3081. 
Hazkani-Covo, E., R. M. Zeller and W. Martin, 2010 Molecular poltergeists: mitochondrial DNA copies (numts) in sequenced nuclear genomes. PLoS Genetics 6: e1000834.

Hershberg, R., and D. A. Petrov, 2010 Evidence that mutation is universally biased towards AT in bacteria. PLoS Genetics 6: e1001115.

Hildebrand, F., A. Meyer and A. Eyre-Walker, 2010 Evidence of selection upon genomic GC-content in bacteria. PLoS Genetics 6: e1001107.

Hoekstra, J. G., M. J. Hipp, T. J. Montine and S. R. Kennedy, 2016 Mitochondrial DNA mutations increase in early stage Alzheimer disease and are inconsistent with oxidative damage. Annals of Neurology 80: 301-306.

Huang, C. Y., N. Grunheit, N. Ahmadinejad, J. N. Timmis and W. Martin, 2005 Mutational decay and age of chloroplast and mitochondrial genomes transferred recently to angiosperm nuclear chromosomes. Plant Physiology 138: 1723-1733.

Jafari, F., S. Zarre, A. Gholipour, F. Eggens, R. K. Rabeler et al., 2020 A new taxonomic backbone for the infrageneric classification of the species-rich genus Silene (Caryophyllaceae). Taxon 69: 337-368.

Johnston, I. G., 2019 Varied mechanisms and models for the varying mitochondrial bottleneck. Frontiers in Cell and Developmental Biology 7: 294.

Joubes, J., and C. Chevalier, 2000 Endoreduplication in higher plants, pp. 191-201 in The Plant Cell Cycle. Springer.

Kennedy, S. R., J. J. Salk, M. W. Schmitt and L. A. Loeb, 2013 Ultra-sensitive sequencing reveals an age-related increase in somatic mitochondrial mutations that are inconsistent with oxidative damage. PLoS Genetics 9: e1003794.

Kennedy, S. R., M. W. Schmitt, E. J. Fox, B. F. Kohrn, J. J. Salk et al., 2014 Detecting ultralowfrequency mutations by Duplex Sequencing. Nature Protocols 9: 2586-2606.

Khakhlova, O., and R. Bock, 2006 Elimination of deleterious mutations in plastid genomes by gene conversion. Plant Journal 46: 85-94.

Kokot, M., M. Długosz and S. Deorowicz, 2017 KMC 3: counting and manipulating k-mer statistics. Bioinformatics 33: 2759-2761.

Langmead, B., and S. L. Salzberg, 2012 Fast gapped-read alignment with Bowtie 2. Nature Methods 9: 357-359.

Lavrov, D. V., and W. Pett, 2016 Animal mitochondrial DNA as we don't know it: mt-genome organization and evolution in non-bilaterian lineages. Genome Biology and Evolution 8: 2896-2913.

Liu, F., W. Fan, J. B. Yang, C. L. Xiang, J. P. Mower et al., 2020 Episodic and guanine-cytosinebiased bursts of intragenomic and interspecific synonymous divergence in Ajugoideae (Lamiaceae) mitogenomes. New Phytologist 228: 1107-1114.

Lough, A. N., L. M. Roark, A. Kato, T. S. Ream, J. C. Lamb et al., 2008 Mitochondrial DNA transfer to the nucleus generates extensive insertion site variation in maize. Genetics 178: 47-55.

Mandel, J. R., A. J. Ramsey, J. M. Holley, V. A. Scott, D. Mody et al., 2020 Disentangling complex inheritance patterns of plant organellar genomes: an example from carrot. Journal of Heredity In Press.

Martin, M., 2011 Cutadapt removes adapter sequences from high-throughput sequencing reads. EMBnet.journal 17: 10-12.

McCauley, D. E., 2013 Paternal leakage, heteroplasmy, and the evolution of plant mitochondrial genomes. New Phytologist 200: 966-977.

McCauley, D. E., M. F. Bailey, N. A. Sherman and M. Z. Darnell, 2005 Evidence for paternal transmission and heteroplasmy in the mitochondrial genome of Silene vulgaris, a gynodioecious plant. Heredity 95: 50-58.

Michalovová, M., B. Vyskot and E. Kejnovsky, 2013 Analysis of plastid and mitochondrial DNA insertions in the nucleus (NUPTs and NUMTs) of six plant species: size, relative age and chromosomal localization. Heredity 111: 314-320. 
Mower, J. P., P. Touzet, J. S. Gummow, L. F. Delph and J. D. Palmer, 2007 Extensive variation in synonymous substitution rates in mitochondrial genes of seed plants. BMC Evolutionary Biology 7: 135.

Noutsos, C., E. Richly and D. Leister, 2005 Generation and evolutionary fate of insertions of organelle DNA in the nuclear genomes of flowering plants. Genome Research 15: 616-628.

Oldenburg, D. J., R. A. Kumar and A. J. Bendich, 2013 The amount and integrity of mtDNA in maize decline with development. Planta 237: 603-617.

Palmer, J. D., K. L. Adams, Y. Cho, C. L. Parkinson, Y.-L. Qiu et al., 2000 Dynamic evolution of plant mitochondrial genomes: mobile genes and introns and highly variable mutation rates. Proceedings of the National Academy of Sciences 97: 6960-6966.

Palmer, J. D., and L. A. Herbon, 1988 Plant mitochondrial DNA evolves rapidly in structure, but slowly in sequence. Journal of Molecular Evolution 28: 87-97.

Parkinson, C. L., J. P. Mower, Y. L. Qiu, A. J. Shirk, K. Song et al., 2005 Multiple major increases and decreases in mitochondrial substitution rates in the plant family Geraniaceae. BMC evolutionary biology 5: 73 .

Preuten, T., E. Cincu, J. Fuchs, R. Zoschke, K. Liere et al., 2010 Fewer genes than organelles: extremely low and variable gene copy numbers in mitochondria of somatic plant cells. Plant Journal 64: 948-959.

Rautenberg, A., D. B. Sloan, V. Aldén and B. Oxelman, 2012 Phylogenetic relationships of Silene multinervia and Silene section Conoimorpha (Caryophyllaceae). Systematic Botany 37: 226237.

Richardson, A. O., D. W. Rice, G. J. Young, A. J. Alverson and J. D. Palmer, 2013 The "fossilized" mitochondrial genome of Liriodendron tulipifera: ancestral gene content and order, ancestral editing sites, and extraordinarily low mutation rate. BMC Biology 11: 29.

Rowan, B. A., D. J. Oldenburg and A. J. Bendich, 2009 A multiple-method approach reveals a declining amount of chloroplast DNA during development in Arabidopsis. BMC Plant Biology 9: 3.

Salk, J. J., M. W. Schmitt and L. A. Loeb, 2018 Enhancing the accuracy of next-generation sequencing for detecting rare and subclonal mutations. Nature Reviews Genetics 19: 269285.

Schmitt, M. W., S. R. Kennedy, J. J. Salk, E. J. Fox, J. B. Hiatt et al., 2012 Detection of ultra-rare mutations by next-generation sequencing. Proceedings of the National Academy of Sciences of the United States of America 109: 14508-14513.

Shaver, J. M., D. J. Oldenburg and A. J. Bendich, 2006 Changes in chloroplast DNA during development in tobacco, Medicago truncatula, pea, and maize. Planta 224: 72-82.

Shen, J., Y. Zhang, M. J. Havey and W. Shou, 2019 Copy numbers of mitochondrial genes change during melon leaf development and are lower than the numbers of mitochondria. Horticulture Research 6: 95.

Skippington, E., T. J. Barkman, D. W. Rice and J. D. Palmer, 2015 Miniaturized mitogenome of the parasitic plant Viscum scurruloideum is extremely divergent and dynamic and has lost all nad genes. Proceedings of the National Academy of Sciences In Press.

Skippington, E., T. J. Barkman, D. W. Rice and J. D. Palmer, 2017 Comparative mitogenomics indicates respiratory competence in parasitic Viscum despite loss of complex I and extreme sequence divergence, and reveals horizontal gene transfer and remarkable variation in genome size. BMC Plant Biology 17: 49.

Sloan, D. B., A. J. Alverson, J. P. Chuckalovcak, M. Wu, D. E. McCauley et al., 2012a Rapid evolution of enormous, multichromosomal genomes in flowering plant mitochondria with exceptionally high mutation rates. PLoS Biology 10: e1001241.

Sloan, D. B., A. J. Alverson, M. Wu, J. D. Palmer and D. R. Taylor, 2012b Recent acceleration of plastid sequence and structural evolution coincides with extreme mitochondrial divergence in the angiosperm genus Silene. Genome Biology and Evolution 4: 294-306.

Sloan, D. B., A. K. Broz, J. Sharbrough and Z. Wu, 2018 Detecting rare mutations and DNA damage with sequencing-based methods. Trends in Biotechnology 36: 729-740. 
Sloan, D. B., A. H. MacQueen, A. J. Alverson, J. D. Palmer and D. R. Taylor, 2010 Extensive loss of RNA editing sites in rapidly evolving Silene mitochondrial genomes: Selection vs. retroprocessing as the driving force. Genetics 185: 1369-1380.

Sloan, D. B., B. Oxelman, A. Rautenberg and D. R. Taylor, 2009 Phylogenetic analysis of mitochondrial substitution rate variation in the angiosperm tribe Sileneae (Caryophyllaceae). BMC Evolutionary Biology 9: 260.

Sloan, D. B., and D. R. Taylor, 2010 Testing for selection on synonymous sites in plant mitochondrial DNA: the role of codon bias and RNA editing. Journal of Molecular Evolution 70: 479-491.

Sloan, D. B., D. A. Triant, M. Wu and D. R. Taylor, 2014 Cytonuclear interactions and relaxed selection accelerate sequence evolution in organelle ribosomes. Molecular Biology and Evolution 31: 673-682.

Sloan, D. B., and Z. Wu, 2014 History of plastid DNA insertions reveals weak deletion and AT mutation biases in angiosperm mitochondrial genomes. Genome Biology and Evolution 6: 3210-3221.

Smith, D. R., and P. J. Keeling, 2015 Mitochondrial and plastid genome architecture: Reoccurring themes, but significant differences at the extremes. Proceedings of the National Academy of Sciences of the United States of America 112: 10177-10184.

Stewart, J. B., and P. F. Chinnery, 2015 The dynamics of mitochondrial DNA heteroplasmy: implications for human health and disease. Nature Reviews Genetics 16: 530-542.

Stupar, R. M., J. W. Lilly, C. D. Town, Z. Cheng, S. Kaul et al., 2001 Complex mtDNA constitutes an approximate $620-\mathrm{kb}$ insertion on Arabidopsis thaliana chromosome 2: implication of potential sequencing errors caused by large-unit repeats. Proceedings of the National Academy of Sciences of the United States of America 98: 5099-5103.

Teixeira, S., K. Foerster and G. Bernasconi, 2009 Evidence for inbreeding depression and postpollination selection against inbreeding in the dioecious plant Silene latifolia. Heredity 102: 101-112.

Weaver, R. J., G. Carrion, R. Nix, G. P. Maeda, S. Rabinowitz et al., 2020 High mitochondrial mutation rates in Silene are associated with nuclear-mediated changes in mitochondrial physiology. Biology Letters 16: 20200450.

Williams, A. M., M. W. Itgen, A. Lambert, A. K. Broz, R. L. Mueller et al., 2020 Long-read transcriptome and other genomic resources for the angiosperm Silene noctiflora. bioRxiv.

Wolfe, K. H., W. H. Li and P. M. Sharp, 1987 Rates of nucleotide substitution vary greatly among plant mitochondrial, chloroplast, and nuclear DNAs. Proceedings of the National Academy of Sciences 84: 9054-9058.

Wu, Z., J. M. Cuthbert, D. R. Taylor and D. B. Sloan, 2015 The massive mitochondrial genome of the angiosperm Silene noctiflora is evolving by gain or loss of entire chromosomes. Proceedings of the National Academy of Sciences 112: 10185-10191.

Wu, Z., and D. B. Sloan, 2019 Recombination and intraspecific polymorphism for the presence and absence of entire chromosomes in mitochondrial genomes. Heredity 122: 647-659.

Wu, Z., G. Waneka, A. K. Broz, C. R. King and D. B. Sloan, 2020a MSH1 is required for maintenance of the low mutation rates in plant mitochondrial and plastid genomes. Proceedings of the National Academy of Sciences In Press.

Wu, Z., G. Waneka and D. B. Sloan, 2020b The tempo and mode of angiosperm mitochondrial genome divergence inferred from intraspecific variation in Arabidopsis thaliana. G3: Genes, Genomes, Genetics 10: 1077-1086.

Wynn, E., E. Purfeerst and A. Christensen, 2020 Mitochondrial DNA repair in an Arabidopsis thaliana uracil N-glycosylase mutant. Plants 9: 261.

Wynn, E. L., and A. C. Christensen, 2015 Are synonymous substitutions in flowering plant mitochondria neutral? Journal of Molecular Evolution 81: 131-135.

Yang, Z., 2007 PAML 4: Phylogenetic Analysis by Maximum Likelihood. Molecular Biology and Evolution 24: 1586-1591.

Zervas, A., G. Petersen and O. Seberg, 2019 Mitochondrial genome evolution in parasitic plants. BMC Evolutionary Biology 19: 87. 
bioRxiv preprint doi: https://doi.org/10.1101/2020.12.09.418582; this version posted February 11, 2021. The copyright holder for this preprint (which was not certified by peer review) is the author/funder, who has granted bioRxiv a license to display the preprint in perpetuity. It is made available under aCC-BY-NC 4.0 International license.

Zhang, H., S. P. Burr and P. F. Chinnery, 2018 The mitochondrial DNA genetic bottleneck: inheritance and beyond. Essays in Biochemistry 62: 225-234.

Zhu, A., W. Guo, S. Gupta, W. Fan and J. P. Mower, 2016 Evolutionary dynamics of the plastid inverted repeat: the effects of expansion, contraction, and loss on substitution rates. New Phytologist 209: 1747-1756. 


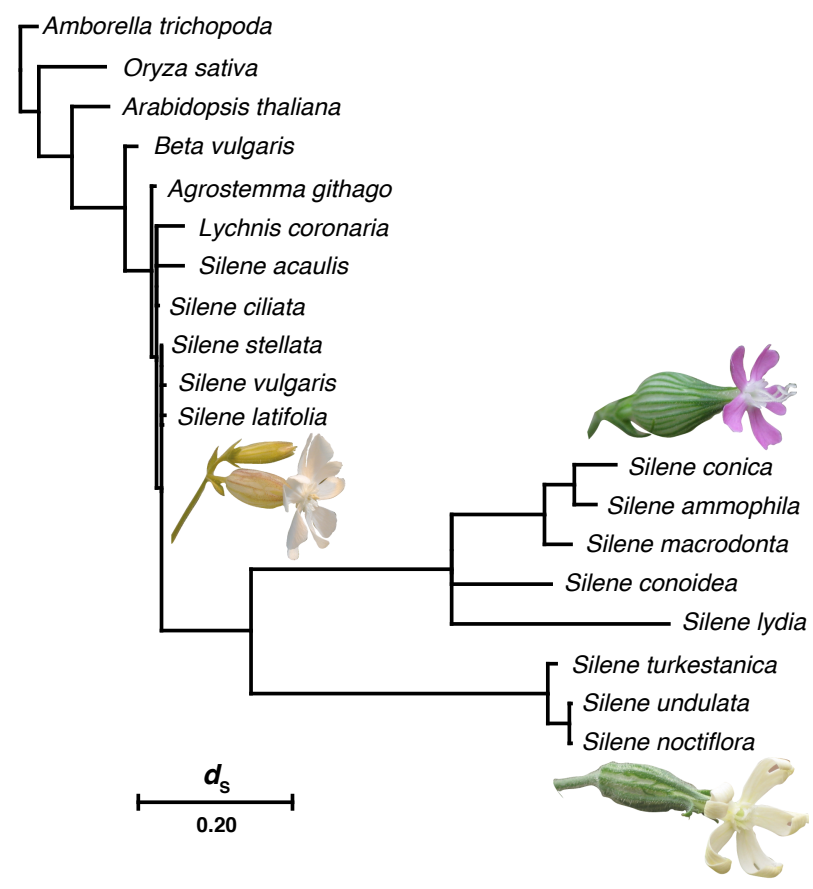

Figure 1. Mitochondrial substitution rate variation among Silene species. Branch lengths are scaled based on synonymous substitutions per site $(d s)$ in a concatenation of three mitochondrial proteincoding genes (atp1, cox3, and nad9) used in previous analyses (SLOAN et al. 2009; RAUTENBERG et al. 2012). Branch lengths were estimated with PAML v4.9j (YANG 2007), using a constrained topology. Note that the two accelerated clades (section Conoimorpha [represented by S. conica] and section Elisanthe [represented by S. noctiflora]) were set as sister groups for this analysis, but there is only weak and inconsistent evidence for that relationship (RAUTENBERG et al. 2012; HAVIRD et al. 2017; JAFARI et al. 2020). Images are shown for each of the three focal species in this study (S. latifolia, S. conica, and S. noctiflora). 


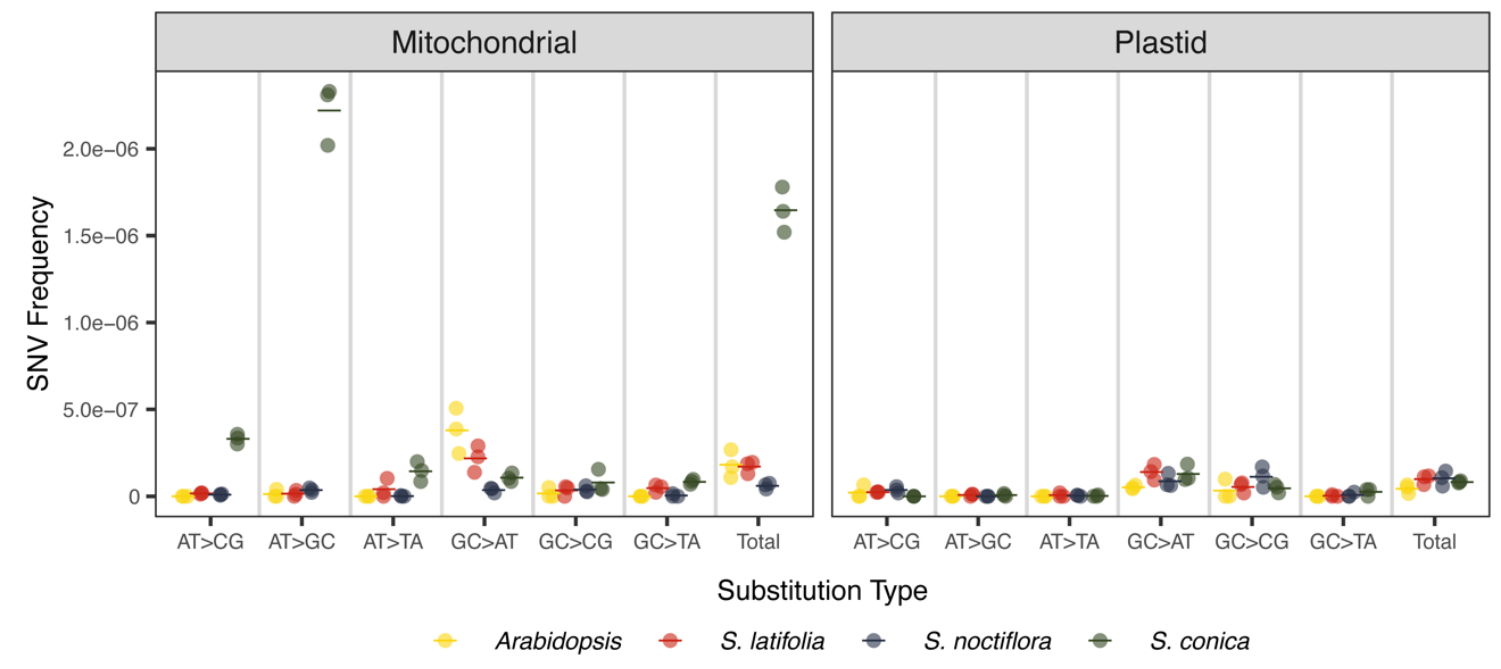

Figure 2. Variation in mitochondrial and plastid SNV frequencies and spectra across Arabidopsis and Silene species. SNV frequencies are calculated as the total number of observed singlenucleotide mismatches in duplex consensus sequence datasets dividided by the total base-pairs of mitochondrial or plastid genome coverage in those datasets (i.e., GC coverage, AT coverage, or total coverage depending on the SNV type). Three biological replicates (circles) are shown for each species, with the mean of those replicates indicated with a horizontal line. The Arabidopsis data points are taken from Wu et al. (2020). The same data are plotted on a log scale in Figure S2. 
A

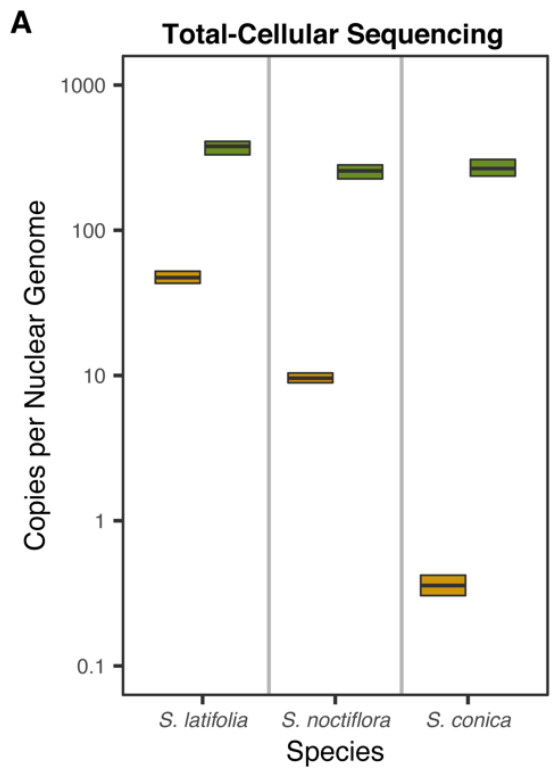

\section{B}

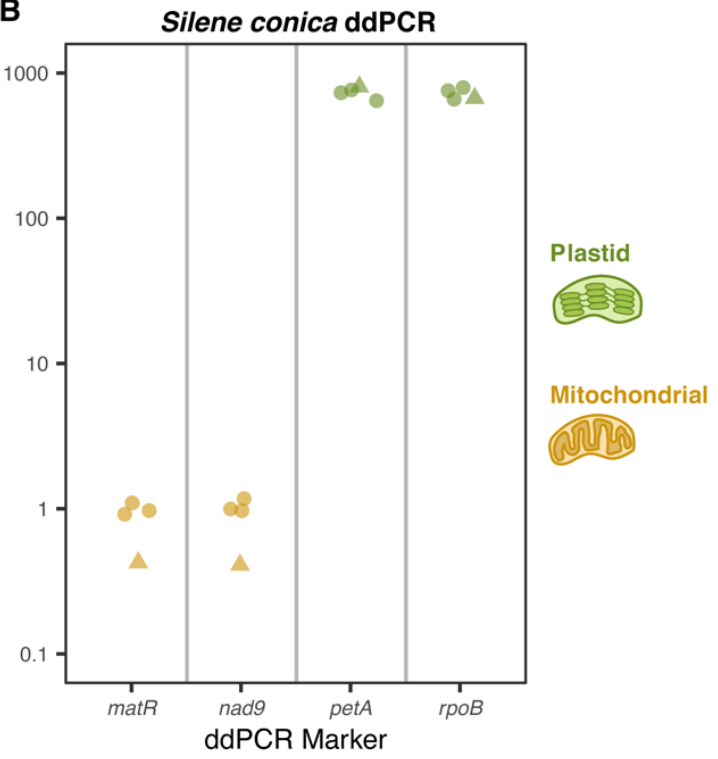

Figure 3. Variation in mitochondrial genome copy number among Silene species. (A) Average mitochondrial, plastid, and nuclear genome copy number were estimated from total-cellular Illuimina shotgun sequencing of leaf tissue from each species. Boxplots show median and interquartile ranges for the ratio of organelle genome copy number to nuclear genome copy number based on scanning the organelle genomes in 2-kb windows. Green and gold boxplots correspond to plastid:nuclear and mitochondrial:nuclear ratios, respectively. (B) ddPCR analysis of mitochondrial and plastid genome copies per nuclear genome copy in $S$. conica. Points are shown for two mitochondrial markers ( $m a t R$ and $n a d 9$ ) and two plastid markers ( $p e t A$ and $r p o B$ ). Estimates for copy number ratios were generated by dividing each mitochondrial or plastid value by the average copy number of two nuclear markers for the corresponding sample (Table S1). The triangles indicate ddPCR estimates for the sample taken from the same DNA extraction used in the original sequencing analysis in part $(A)$. The circles represent the three new samples collected for this ddPCR analysis. 


\section{SUPPLEMENTARY MATERIAL}

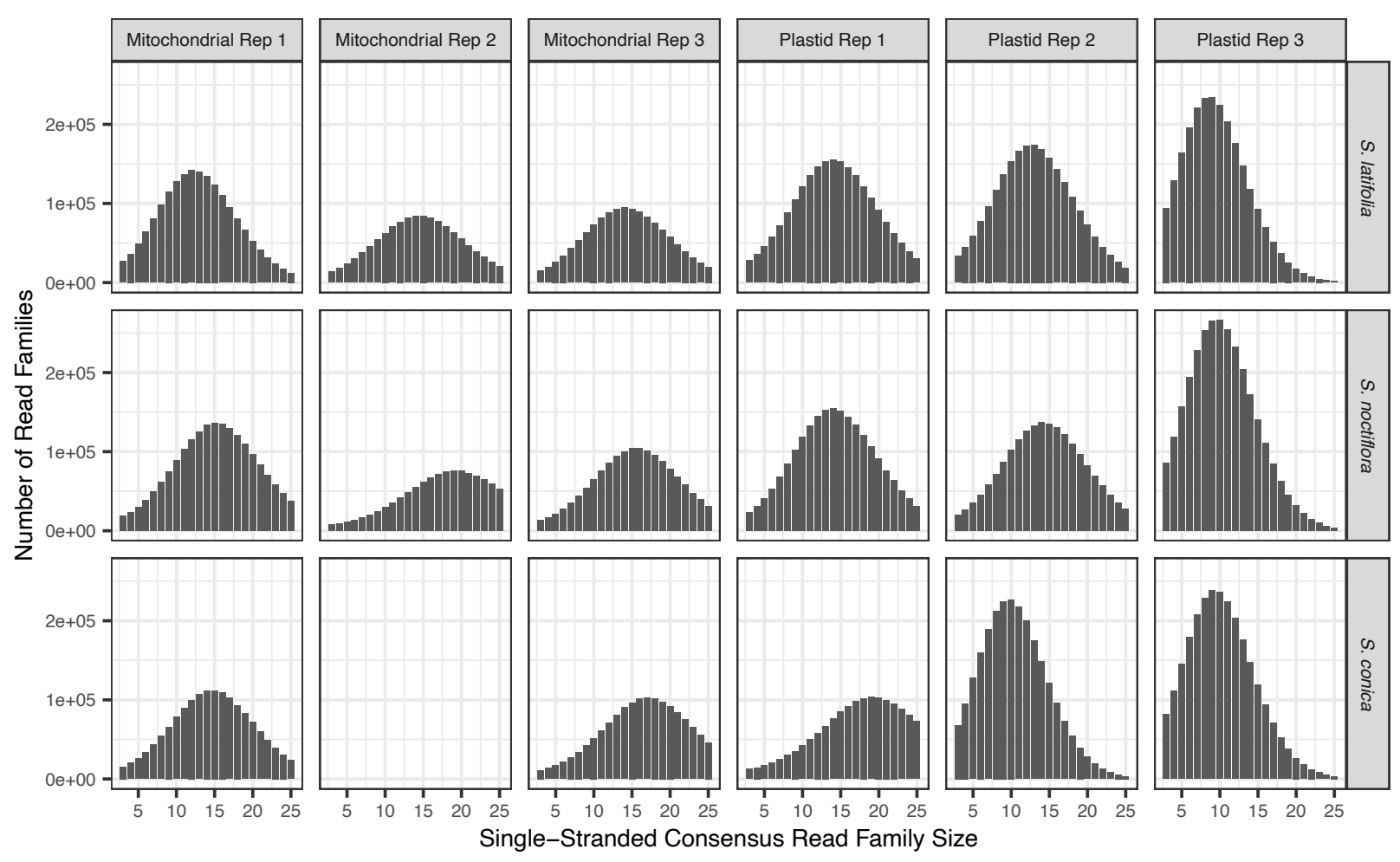

Figure S1. Summary of family sizes for single-stranded consensus sequences used for generation of double-stranded consensus sequences for each Duplex Sequencing library. The analysis pipeline required a minimum family size of 3 reads for each of the two complementary single-stranded families. The mitochondrial DNA library for the second biological replicate from S. conica was not sequenced because of an apparent library loading error. 
bioRxiv preprint doi: https://doi.org/10.1101/2020.12.09.418582; this version posted February 11,2021 . The copyright holder for this preprint (which was not certified by peer review) is the author/funder, who has granted bioRxiv a license to display the preprint in perpetuity. It is made available under aCC-BY-NC 4.0 International license.

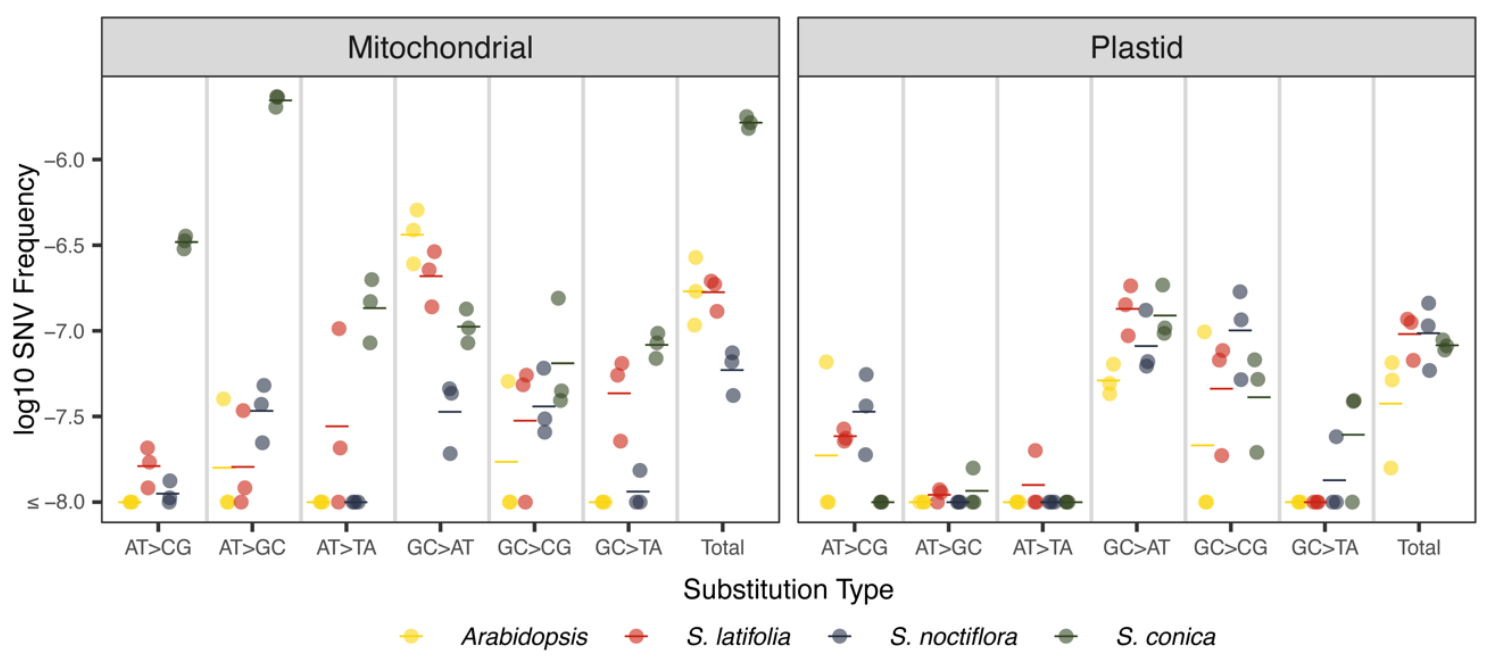

Figure S2. Variation in mitochondrial and plastid SNV frequencies and spectra across Arabidopsis and Silene species. The same data shown in Figure 2 are plotted on a log scale here. 
bioRxiv preprint doi: https://doi.org/10.1101/2020.12.09.418582. this version posted February 11,2021 . The copyright holder for this preprint (which was not certified by peer review) is the author/funder, who has granted bioRxiv a license to display the preprint in perpetuity. It is made available under aCC-BY-NC 4.0 International license.

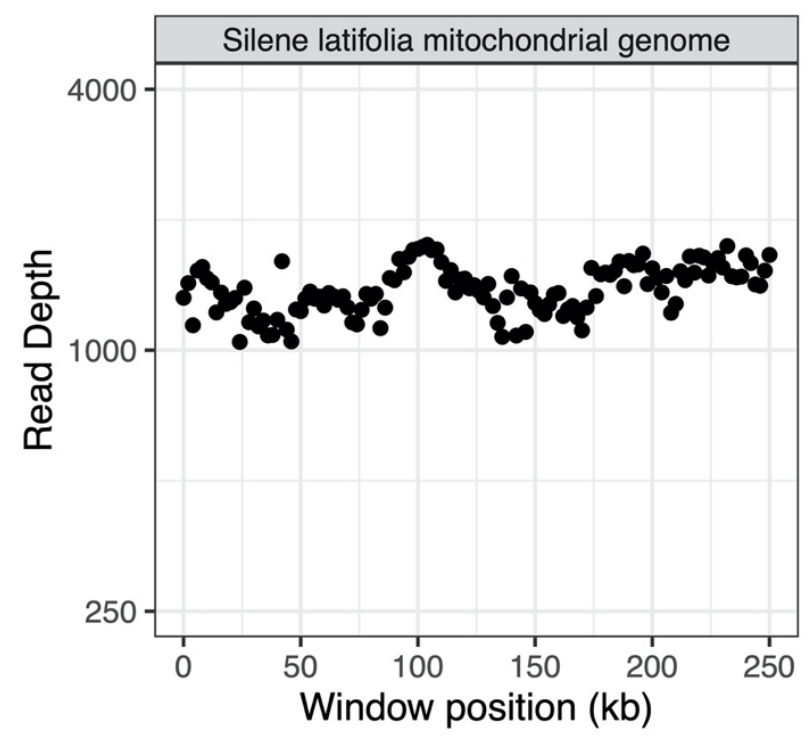

Figure S3. Summary of mitochondrial genome coverage in the S. latifolia UK2600 total-cellular sequencing library. Coverage is estimated based on reads mapping with a maximum of one mismatch and no indels in 2-kb windows. 


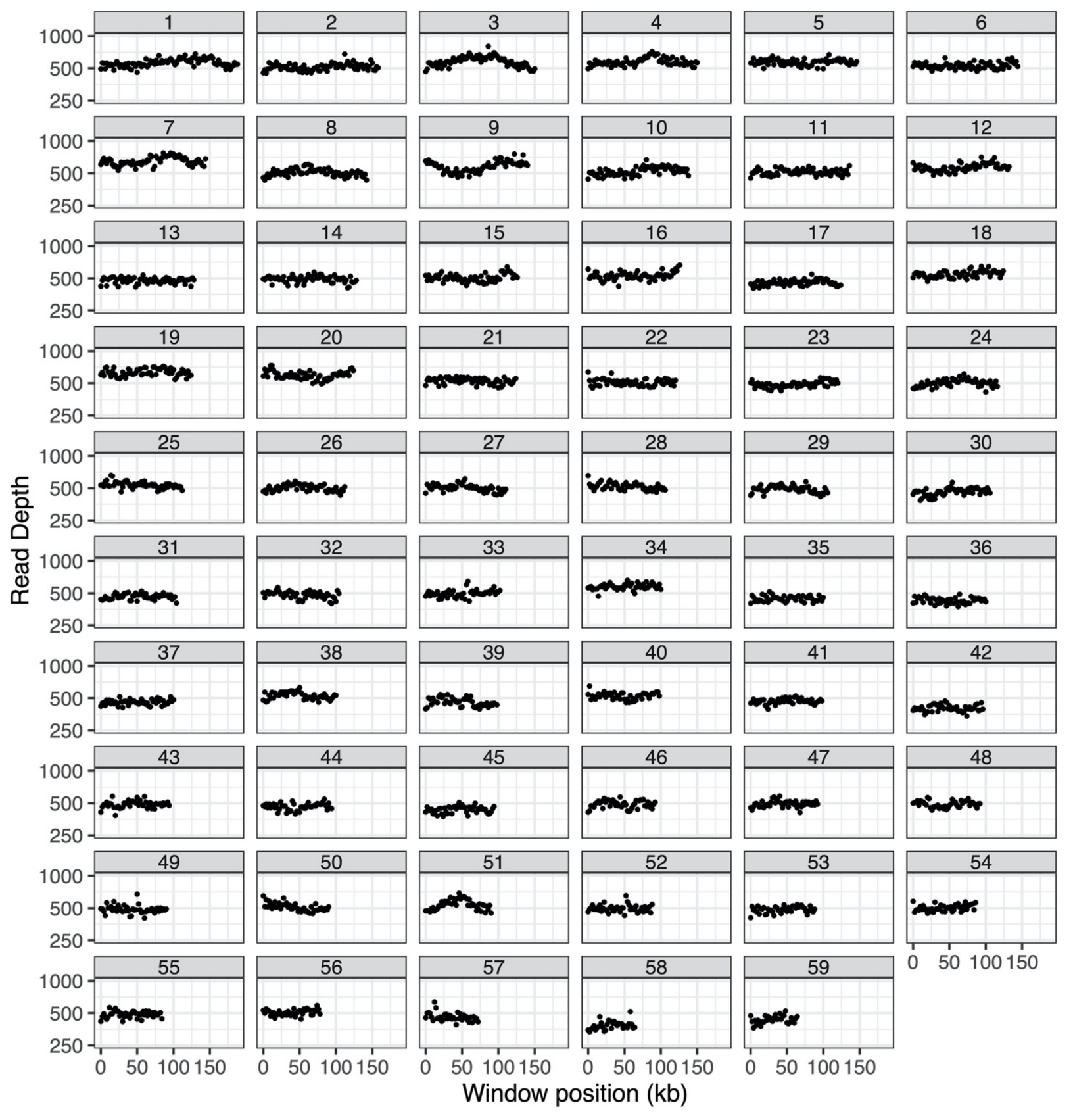

Figure S4. Summary of mitochondrial genome coverage in the S. noctiflora OSR total-cellular sequencing library. Coverage is estimated based on reads mapping with a maximum of one mismatch and no indels in 2-kb windows. Each panel represents a different chromosome within the multichromosomal genome. 


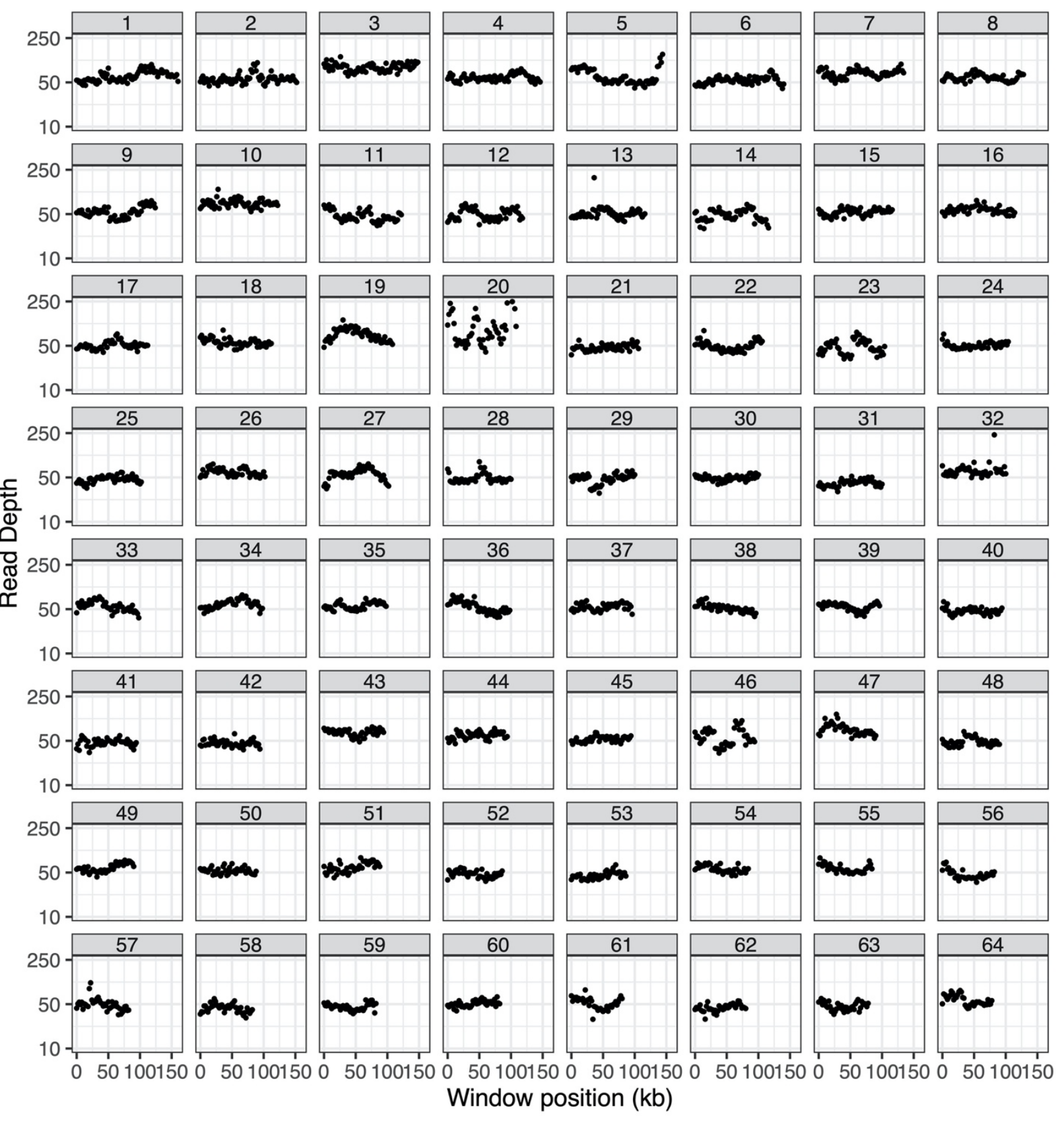

Figure S5a. Summary of coverage for mitochondrial chromosomes 1 through 64 in the S. conica ABR total-cellular sequencing library. Coverage is estimated based on reads mapping with a maximum of one mismatch and no indels in 2-kb windows. Note that four of the data points on chromosome 20 and two of the data points on chromosome 32 exceeded a coverage of $250 \times$ and are not shown to improve readability of the plots. 


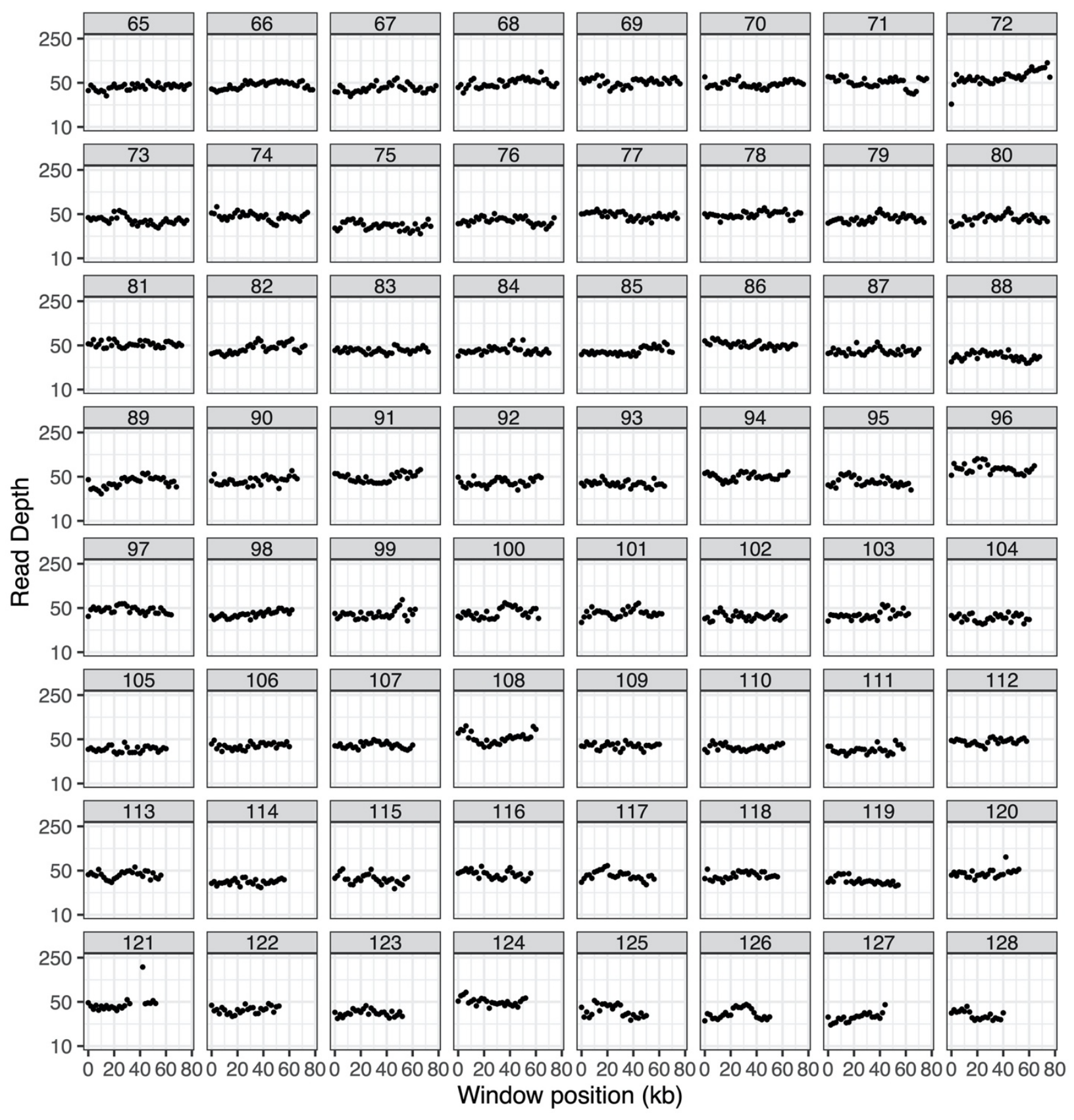

Figure S5b. Summary of coverage for mitochondrial chromosomes 65 through 128 in the S. conica ABR total-cellular sequencing library. Coverage is estimated based on reads mapping with a maximum of one mismatch and no indels in 2-kb windows. Note that four of the data points on chromosome 121 exceeded a coverage of $250 \times$ and are not shown to improve readability of the plots. 
bioRxiv preprint doi: https://doi.org/10.1101/202012 09.418582. this version posted February 11 2021. The copyright holder for this preprint (which was not certified by peer review) is the author/funder, who has granted bioRxiv a license to display the preprint in perpetuity. It is made available under aCC-BY-NC 4.0 International license.

Table S1. Primers used in the S. conica ddPCR analysis. The two nuclear markers are referred to by the identifiers for the homologs in Arabidopsis thaliana.

\begin{tabular}{llll}
\hline Gene & Genome & Forward Primer & Reverse Primer \\
\hline nad9 & mitochondrial & CAAGAAGTGGTCAAAAGAATG & CGAGAATAAAACGAGTACTCAG \\
matR & mitochondrial & GATCAGAATGGTACCCGAATC & CCTTGAAGATTGCTAGGAGTTG \\
rpoB & plastid & CGGGAGATGCAAGAACAAAC & CTGATCTTCCTCCCCAATCTG \\
petA & plastid & CTATCCCATTTTGCCCAGC & CCCCTTTCTTGCCGTTAGC \\
AT1G06040 & nuclear & CCTTTATCTTCTGTGTGAGG & GGCTGTGCACTTTGGTGG \\
AT1G07630 & nuclear & CAGAAAAAGTGGAATGATGCTC & CAATGAGATGAAGTGCTCTACC \\
\hline
\end{tabular}


bioRxiv preprint doi: https://doi.org/10.1101/2020.12.09.418582; this version posted February 11, 2021. The copyright holder for this preprint (which was not certified by peer review) is the author/funder, who has granted bioRxiv a license to display the preprint in perpetuity. It is made available under aCC-BY-NC 4.0 International license.

Table S2. Summary of library sequencing and mapping. Reported coverage values and mapping percentages are for duplex consensus sequences.

\begin{tabular}{|c|c|c|c|c|c|c|c|c|}
\hline Library & Library Type & SRA Accession & $\begin{array}{r}\text { Raw Read } \\
\text { Pairs }\end{array}$ & $\begin{array}{r}\text { Mito Coverage } \\
\text { (bp) }\end{array}$ & $\begin{array}{r}\text { Plastid } \\
\text { Coverage (bp) }\end{array}$ & $\begin{array}{r}\text { Mito } \\
\text { Mapping (\%) }\end{array}$ & $\begin{array}{r}\text { Plastid } \\
\text { Mapping (\%) }\end{array}$ & $\begin{array}{r}\text { Unmapped } \\
\text { (\%) }\end{array}$ \\
\hline Silene conica chloroplast 1 & Chloroplast duplex & SAMN17011097 & $1.15 \mathrm{E}+08$ & $9.25 \mathrm{E}+07$ & $2.03 \mathrm{E}+08$ & $29.49 \%$ & $64.88 \%$ & $5.63 \%$ \\
\hline Silene conica chloroplast 2 & Chloroplast duplex & SAMN17011098 & $1.15 \mathrm{E}+08$ & $1.33 E+08$ & $2.72 E+08$ & $31.48 \%$ & $64.13 \%$ & $4.39 \%$ \\
\hline Silene conica chloroplast 3 & Chloroplast duplex & SAMN17011099 & $1.42 \mathrm{E}+08$ & $1.37 \mathrm{E}+08$ & $2.70 \mathrm{E}+08$ & $31.72 \%$ & $62.55 \%$ & $5.73 \%$ \\
\hline Silene conica mito 1 & Mitochondrial duplex & SAMN17011100 & $1.01 \mathrm{E}+08$ & $2.18 \mathrm{E}+08$ & $1.77 \mathrm{E}+07$ & $80.87 \%$ & $6.58 \%$ & $12.55 \%$ \\
\hline Silene conica mito 3 & Mitochondrial duplex & SAMN17011101 & $1.14 \mathrm{E}+08$ & $2.16 \mathrm{E}+08$ & $2.01 \mathrm{E}+07$ & $77.21 \%$ & $7.16 \%$ & $15.63 \%$ \\
\hline Silene latifolia chloroplast 1 & Chloroplast duplex & SAMN17011085 & $1.33 E+08$ & $2.89 \mathrm{E}+07$ & $2.83 E+08$ & $7.39 \%$ & $72.35 \%$ & $20.26 \%$ \\
\hline Silene latifolia chloroplast 2 & Chloroplast duplex & SAMN17011086 & $1.28 \mathrm{E}+08$ & $3.54 \mathrm{E}+07$ & $2.41 \mathrm{E}+08$ & $8.82 \%$ & $60.10 \%$ & $31.08 \%$ \\
\hline Silene latifolia chloroplast 3 & Chloroplast duplex & SAMN17011087 & $1.01 \mathrm{E}+08$ & $3.68 \mathrm{E}+07$ & $2.73 E+08$ & $9.13 \%$ & $67.73 \%$ & $23.14 \%$ \\
\hline Silene latifolia mito 1 & Mitochondrial duplex & SAMN17011088 & $1.13 E+08$ & 1.16E+08 & $2.67 \mathrm{E}+07$ & $38.26 \%$ & $8.83 \%$ & $52.91 \%$ \\
\hline Silene latifolia mito 2 & Mitochondrial duplex & SAMN17011089 & $9.79 \mathrm{E}+07$ & $4.93 E+07$ & $1.63 E+07$ & $24.87 \%$ & $8.21 \%$ & $66.92 \%$ \\
\hline Silene latifolia mito 3 & Mitochondrial duplex & SAMN17011090 & $8.83 E+07$ & $6.56 \mathrm{E}+07$ & $2.23 \mathrm{E}+07$ & $27.94 \%$ & $9.48 \%$ & $62.58 \%$ \\
\hline Silene noctiflora chloroplast 1 & Chloroplast duplex & SAMN17011091 & $1.37 \mathrm{E}+08$ & $1.06 \mathrm{E}+08$ & $2.55 \mathrm{E}+08$ & $27.63 \%$ & $66.35 \%$ & $6.02 \%$ \\
\hline Silene noctiflora chloroplast 2 & Chloroplast duplex & SAMN17011092 & $1.25 \mathrm{E}+08$ & $9.39 \mathrm{E}+07$ & $2.20 \mathrm{E}+08$ & $28.18 \%$ & $66.12 \%$ & $5.70 \%$ \\
\hline Silene noctiflora chloroplast 3 & Chloroplast duplex & SAMN17011093 & $1.37 \mathrm{E}+08$ & $1.25 \mathrm{E}+08$ & $3.19 \mathrm{E}+08$ & $25.69 \%$ & $65.36 \%$ & $8.95 \%$ \\
\hline Silene noctiflora mito 2 & Mitochondrial duplex & SAMN17011095 & $1.06 \mathrm{E}+08$ & $1.88 \mathrm{E}+08$ & $1.22 \mathrm{E}+07$ & $81.54 \%$ & $5.28 \%$ & $13.18 \%$ \\
\hline Silene noctiflora mito 3 & Mitochondrial duplex & SAMN17011096 & $1.03 E+08$ & $1.93 E+08$ & $2.39 \mathrm{E}+07$ & $71.53 \%$ & $8.84 \%$ & $19.63 \%$ \\
\hline Silene conica ABR & Total cellular shotgun & SAMN17011105 & $4.98 \mathrm{E}+08$ & $3.53 E+08$ & $1.68 \mathrm{E}+09$ & $0.49 \%$ & $2.31 \%$ & $97.20 \%$ \\
\hline Silene noctiflora OSR & Total cellular shotgun & SAMN17011104 & $5.76 \mathrm{E}+08$ & $3.45 \mathrm{E}+09$ & $2.10 \mathrm{E}+09$ & $2.51 \%$ & $1.53 \%$ & $95.96 \%$ \\
\hline Silene latifolia UK2600 & Total cellular shotgun & SAMN17011102 & $2.81 \mathrm{E}+08$ & $5.95 \mathrm{E}+08$ & $5.51 \mathrm{E}+09$ & $0.50 \%$ & $4.64 \%$ & $94.86 \%$ \\
\hline Silene latifolia Kew 32982 & Total cellular shotgun & SAMN17011103 & $3.04 \mathrm{E}+08$ & & & & & \\
\hline
\end{tabular}


bioRxiv preprint doi: https://doi.org/10.1101/2020.12.09.418582; this version posted February 11, 2021. The copyright holder for this preprint (which was not certified by peer review) is the author/funder, who has granted bioRxiv a license to display the preprint in perpetuity. It is made available under aCC-BY-NC 4.0 International license.

Table S3. Silene mitochondrial SNV count and frequency data with and without $k$-mer filtering

\begin{tabular}{|c|c|c|c|c|c|c|c|c|c|c|c|c|c|c|c|c|}
\hline \multirow[b]{2}{*}{ Species } & \multirow[b]{2}{*}{ Rep } & \multirow[b]{2}{*}{ k-mer Filt } & \multicolumn{7}{|c|}{ SNV Counts } & \multicolumn{7}{|c|}{ SNV Frequencies } \\
\hline & & & $A>C$ & $A>G$ & $A>T$ & $C>A$ & $C>G$ & $C>T$ & Total & $A>C$ & $A>G$ & $A>T$ & $C>A$ & $C>G$ & $C>T$ & Total \\
\hline Silene conica & 1 & 10 & 53 & 356 & 26 & 13 & 6 & 18 & 472 & $3.0 \mathrm{E}-07$ & $2.0 \mathrm{E}-06$ & $1.5 \mathrm{E}-07$ & $9.7 \mathrm{E}-08$ & 4.5E-08 & $1.3 \mathrm{E}-07$ & $1.5 \mathrm{E}-06$ \\
\hline Silene conica & 2 & 10 & 27 & 176 & 15 & 4 & 9 & 6 & 237 & 3.6E-07 & 2.3E-06 & 2.0E-07 & $6.9 \mathrm{E}-08$ & $1.6 \mathrm{E}-07$ & $1.0 \mathrm{E}-07$ & $1.8 \mathrm{E}-06$ \\
\hline Silene conica & 3 & 10 & 67 & 462 & 17 & 13 & 6 & 13 & 578 & 3.3E-07 & 2.3E-06 & $8.5 \mathrm{E}-08$ & $8.5 \mathrm{E}-08$ & $3.9 \mathrm{E}-08$ & $8.5 \mathrm{E}-08$ & 1.6E-06 \\
\hline Silene conica & 1 & None & 150 & 483 & 58 & 49 & 12 & 217 & 969 & $8.5 \mathrm{E}-07$ & 2.7E-06 & $3.3 \mathrm{E}-07$ & $3.6 \mathrm{E}-07$ & $8.9 \mathrm{E}-08$ & 1.6E-06 & 3.1E-06 \\
\hline Silene conica & 2 & None & 64 & 238 & 24 & 20 & 12 & 98 & 456 & $8.5 \mathrm{E}-07$ & $3.2 \mathrm{E}-06$ & 3.2E-07 & $3.5 \mathrm{E}-07$ & $2.1 \mathrm{E}-07$ & 1.7E-06 & 3.4E-06 \\
\hline Silene conica & 3 & None & 158 & 610 & 50 & 59 & 17 & 231 & 1125 & $7.9 \mathrm{E}-07$ & $3.0 \mathrm{E}-06$ & 2.5E-07 & $3.9 \mathrm{E}-07$ & $1.1 \mathrm{E}-07$ & $1.5 \mathrm{E}-06$ & $3.2 \mathrm{E}-06$ \\
\hline Silene latifolia & 1 & 10 & 1 & 1 & 0 & 4 & 3 & 18 & 27 & 5.7E-09 & $5.7 \mathrm{E}-09$ & $0.0 \mathrm{E}+00$ & $3.0 \mathrm{E}-08$ & 2.2E-08 & $1.3 \mathrm{E}-07$ & $8.7 \mathrm{E}-08$ \\
\hline Silene latifolia & 2 & 10 & 1 & 0 & 1 & 2 & 2 & 5 & 11 & $1.3 \mathrm{E}-08$ & $0.0 \mathrm{E}+00$ & $1.3 \mathrm{E}-08$ & $3.5 \mathrm{E}-08$ & $3.5 \mathrm{E}-08$ & $8.6 \mathrm{E}-08$ & $8.2 \mathrm{E}-08$ \\
\hline Silene latifolia & 3 & 10 & 1 & 2 & 6 & 1 & 0 & 10 & 20 & $5.0 \mathrm{E}-09$ & $1.0 \mathrm{E}-08$ & $3.0 \mathrm{E}-08$ & $6.5 \mathrm{E}-09$ & $0.0 \mathrm{E}+00$ & $6.5 \mathrm{E}-08$ & $5.7 \mathrm{E}-08$ \\
\hline Silene latifolia & 1 & None & 9 & 8 & 6 & 17 & 5 & 42 & 87 & $1.1 \mathrm{E}-07$ & $9.7 \mathrm{E}-08$ & 7.3E-08 & 2.7E-07 & $8.1 \mathrm{E}-08$ & $6.8 \mathrm{E}-07$ & $6.0 \mathrm{E}-07$ \\
\hline Silene latifolia & 2 & None & 5 & 8 & 14 & 17 & 6 & 58 & 108 & $1.0 \mathrm{E}-07$ & 1.7E-07 & $2.9 \mathrm{E}-07$ & 4.7E-07 & $1.7 \mathrm{E}-07$ & $1.6 \mathrm{E}-06$ & $1.3 \mathrm{E}-06$ \\
\hline Silene latifolia & 3 & None & 9 & 16 & 18 & 19 & 10 & 52 & 124 & $1.5 \mathrm{E}-07$ & 2.7E-07 & $3.1 \mathrm{E}-07$ & 4.3E- 07 & $2.3 \mathrm{E}-07$ & $1.2 \mathrm{E}-06$ & $1.2 \mathrm{E}-06$ \\
\hline Silene noctiflora & 1 & 10 & 3 & 5 & 1 & 0 & 4 & 3 & 16 & $1.3 \mathrm{E}-08$ & $2.2 \mathrm{E}-08$ & 4.4E-09 & $0.0 \mathrm{E}+00$ & $2.6 \mathrm{E}-08$ & $1.9 \mathrm{E}-08$ & $4.2 \mathrm{E}-08$ \\
\hline Silene noctiflora & 2 & 10 & 1 & 8 & 0 & 0 & 7 & 5 & 21 & $6.0 \mathrm{E}-09$ & $4.8 \mathrm{E}-08$ & $0.0 \mathrm{E}+00$ & $0.0 \mathrm{E}+00$ & $6.1 \mathrm{E}-08$ & $4.3 \mathrm{E}-08$ & 7.4E-08 \\
\hline Silene noctiflora & 3 & 10 & 2 & 7 & 0 & 2 & 4 & 6 & 21 & $1.1 \mathrm{E}-08$ & $3.7 \mathrm{E}-08$ & $0.0 \mathrm{E}+00$ & $1.5 \mathrm{E}-08$ & $3.1 \mathrm{E}-08$ & $4.6 \mathrm{E}-08$ & $6.6 \mathrm{E}-08$ \\
\hline Silene noctiflora & 1 & None & 3 & 8 & 3 & 4 & 6 & 12 & 36 & $1.3 \mathrm{E}-08$ & $3.5 \mathrm{E}-08$ & $1.3 \mathrm{E}-08$ & 2.6E-08 & $3.8 \mathrm{E}-08$ & 7.7E-08 & $9.4 \mathrm{E}-08$ \\
\hline Silene noctiflora & 2 & None & 2 & 11 & 1 & 2 & 13 & 9 & 38 & $1.2 \mathrm{E}-08$ & $6.6 \mathrm{E}-08$ & $6.0 \mathrm{E}-09$ & 1.7E-08 & $1.1 \mathrm{E}-07$ & $7.8 \mathrm{E}-08$ & $1.3 \mathrm{E}-07$ \\
\hline Silene noctiflora & 3 & None & 5 & 13 & 2 & 11 & 9 & 11 & 51 & $2.7 \mathrm{E}-08$ & $6.9 \mathrm{E}-08$ & $1.1 \mathrm{E}-08$ & $8.4 \mathrm{E}-08$ & $6.9 \mathrm{E}-08$ & $8.4 \mathrm{E}-08$ & $1.6 \mathrm{E}-07$ \\
\hline
\end{tabular}


bioRxiv preprint doi: https://doi.org/10.1101/2020.12.09.418582; this version posted February 11, 2021. The copyright holder for this preprint (which was not certified by peer review) is the author/funder, who has granted bioRxiv a license to display the preprint in perpetuity. It is made available under aCC-BY-NC 4.0 International license.

Table S4. Silene plastid SNV count and frequency data with and without $k$-mer filtering

\begin{tabular}{|c|c|c|c|c|c|c|c|c|c|c|c|c|c|c|c|c|}
\hline \multirow[b]{2}{*}{ Species } & \multirow[b]{2}{*}{ Rep } & \multirow[b]{2}{*}{ k-mer Filt } & \multicolumn{7}{|c|}{ SNV Counts } & \multicolumn{7}{|c|}{ SNV Frequencies } \\
\hline & & & $A>C$ & $A>G$ & $A>T$ & $C>A$ & $C>G$ & $C>T$ & Total & $A>C$ & $A>G$ & $A>T$ & $C>A$ & $\mathbf{C}>\mathbf{G}$ & $C>T$ & Total \\
\hline Silene conica & 1 & 10 & 0 & 2 & 1 & 3 & 4 & 8 & 18 & $0.0 \mathrm{E}+00$ & $1.6 \mathrm{E}-08$ & $7.9 \mathrm{E}-09$ & $3.9 \mathrm{E}-08$ & $5.2 \mathrm{E}-08$ & $1.0 \mathrm{E}-07$ & $8.8 \mathrm{E}-08$ \\
\hline Silene conica & 2 & 10 & 0 & 0 & 0 & 4 & 7 & 10 & 21 & $0.0 \mathrm{E}+00$ & $0.0 \mathrm{E}+00$ & $0.0 \mathrm{E}+00$ & $3.9 \mathrm{E}-08$ & $6.8 \mathrm{E}-08$ & $9.7 \mathrm{E}-08$ & $7.7 \mathrm{E}-08$ \\
\hline Silene conica & 3 & 10 & 0 & 1 & 0 & 0 & 2 & 19 & 22 & $0.0 \mathrm{E}+00$ & $6.0 \mathrm{E}-09$ & $0.0 \mathrm{E}+00$ & $0.0 \mathrm{E}+00$ & $2.0 \mathrm{E}-08$ & $1.9 \mathrm{E}-07$ & $8.2 \mathrm{E}-08$ \\
\hline Silene conica & 1 & None & 1 & 4 & 1 & 3 & 4 & 12 & 25 & 7.9E-09 & 3.2E-08 & 7.9E-09 & $3.9 \mathrm{E}-08$ & $5.2 \mathrm{E}-08$ & 1.6E-07 & $1.2 \mathrm{E}-07$ \\
\hline Silene conica & 2 & None & 0 & 0 & 0 & 6 & 8 & 20 & 34 & $0.0 \mathrm{E}+00$ & $0.0 \mathrm{E}+00$ & $0.0 \mathrm{E}+00$ & $5.8 \mathrm{E}-08$ & 7.7E-08 & $1.9 \mathrm{E}-07$ & $1.3 \mathrm{E}-07$ \\
\hline Silene conica & 3 & None & 0 & 1 & 1 & 2 & 4 & 26 & 34 & $0.0 \mathrm{E}+00$ & $6.0 \mathrm{E}-09$ & $6.0 \mathrm{E}-09$ & $2.0 \mathrm{E}-08$ & 3.9E-08 & $2.5 \mathrm{E}-07$ & $1.3 \mathrm{E}-07$ \\
\hline Silene latifolia & 1 & 10 & 4 & 2 & 0 & 1 & 2 & 10 & 19 & $2.3 \mathrm{E}-08$ & $1.1 \mathrm{E}-08$ & $0.0 \mathrm{E}+00$ & $9.4 \mathrm{E}-09$ & $1.9 \mathrm{E}-08$ & $9.4 \mathrm{E}-08$ & $6.7 \mathrm{E}-08$ \\
\hline Silene latifolia & 2 & 10 & 4 & 0 & 3 & 0 & 7 & 13 & 27 & $2.7 \mathrm{E}-08$ & $0.0 \mathrm{E}+00$ & $2.0 \mathrm{E}-08$ & $0.0 \mathrm{E}+00$ & 7.7E-08 & $1.4 \mathrm{E}-07$ & $1.1 \mathrm{E}-07$ \\
\hline Silene latifolia & 3 & 10 & 4 & 2 & 0 & 0 & 7 & 19 & 32 & $2.4 \mathrm{E}-08$ & $1.2 \mathrm{E}-08$ & $0.0 \mathrm{E}+00$ & $0.0 \mathrm{E}+00$ & $6.7 \mathrm{E}-08$ & $1.8 \mathrm{E}-07$ & $1.2 \mathrm{E}-07$ \\
\hline Silene latifolia & 1 & None & 8 & 6 & 4 & 2 & 3 & 31 & 54 & $4.5 \mathrm{E}-08$ & 3.4E-08 & $2.3 \mathrm{E}-08$ & $1.9 \mathrm{E}-08$ & $2.8 \mathrm{E}-08$ & $2.9 \mathrm{E}-07$ & $1.9 \mathrm{E}-07$ \\
\hline Silene latifolia & 2 & None & 10 & 4 & 11 & 10 & 10 & 38 & 83 & $6.7 \mathrm{E}-08$ & $2.7 \mathrm{E}-08$ & 7.3E-08 & 1.1E-07 & 1.1E-07 & 4.2E-07 & $3.4 \mathrm{E}-07$ \\
\hline Silene latifolia & 3 & None & 7 & 12 & 6 & 6 & 9 & 30 & 70 & 4.1E-08 & 7.1E-08 & 3.5E-08 & $5.8 \mathrm{E}-08$ & 8.7E-08 & $2.9 \mathrm{E}-07$ & $2.6 \mathrm{E}-07$ \\
\hline Silene noctiflora & 1 & 10 & 3 & 0 & 1 & 0 & 5 & 6 & 15 & $1.9 \mathrm{E}-08$ & $0.0 \mathrm{E}+00$ & $6.3 \mathrm{E}-09$ & $0.0 \mathrm{E}+00$ & $5.2 \mathrm{E}-08$ & $6.2 \mathrm{E}-08$ & $5.9 \mathrm{E}-08$ \\
\hline Silene noctiflora & 2 & 10 & 5 & 0 & 0 & 2 & 14 & 11 & 32 & $3.6 \mathrm{E}-08$ & $0.0 \mathrm{E}+00$ & $0.0 \mathrm{E}+00$ & $2.4 \mathrm{E}-08$ & $1.7 \mathrm{E}-07$ & $1.3 \mathrm{E}-07$ & $1.5 \mathrm{E}-07$ \\
\hline Silene noctiflora & 3 & 10 & 11 & 0 & 1 & 0 & 14 & 8 & 34 & $5.6 \mathrm{E}-08$ & $0.0 \mathrm{E}+00$ & $5.1 \mathrm{E}-09$ & $0.0 \mathrm{E}+00$ & $1.2 \mathrm{E}-07$ & $6.6 \mathrm{E}-08$ & $1.1 \mathrm{E}-07$ \\
\hline Silene noctiflora & 1 & None & 5 & 1 & 1 & 1 & 5 & 9 & 22 & 3.1E-08 & $6.3 \mathrm{E}-09$ & $6.3 \mathrm{E}-09$ & $1.0 \mathrm{E}-08$ & $5.2 \mathrm{E}-08$ & $9.3 \mathrm{E}-08$ & $8.6 \mathrm{E}-08$ \\
\hline Silene noctiflora & 2 & None & 6 & 1 & 0 & 2 & 14 & 19 & 42 & 4.4E-08 & 7.3E-09 & $0.0 \mathrm{E}+00$ & $2.4 \mathrm{E}-08$ & 1.7E-07 & 2.3E-07 & $1.9 \mathrm{E}-07$ \\
\hline Silene noctiflora & 3 & None & 12 & 0 & 2 & 2 & 14 & 17 & 47 & $6.1 \mathrm{E}-08$ & $0.0 \mathrm{E}+00$ & $1.0 \mathrm{E}-08$ & 1.7E-08 & $1.2 \mathrm{E}-07$ & $1.4 \mathrm{E}-07$ & $1.5 \mathrm{E}-07$ \\
\hline
\end{tabular}


bioRxiv preprint doi: https://doi.org/10.1101/2020.12.09.418582; this version posted February 11, 2021. The copyright holder for this preprint (which was not certified by peer review) is the author/funder, who has granted bioRxiv a license to display the preprint in perpetuity. It is made available under aCC-BY-NC 4.0 International license.

Table S5. Genome copy number estimates

\begin{tabular}{|c|c|c|c|c|c|c|c|c|c|c|c|}
\hline Species & $\begin{array}{r}\text { Nuclear } \\
\text { (=Unmapped) } \\
\text { Coverage (bp) }\end{array}$ & $\begin{array}{r}\text { Mito } \\
\text { Coverage } \\
\text { (bp) }\end{array}$ & $\begin{array}{r}\text { Plastid } \\
\text { Coverage } \\
\text { (bp) }\end{array}$ & $\begin{array}{l}\text { Nuclear } \\
\text { Genome } \\
\text { Size (bp) }\end{array}$ & $\begin{array}{r}\text { Mito } \\
\text { Genome } \\
\text { Size (bp) }\end{array}$ & $\begin{array}{r}\text { Plastid } \\
\text { Genome } \\
\text { Size (bp) }\end{array}$ & $\begin{array}{r}\text { Nuclear } \\
\text { Cov. }\end{array}$ & $\begin{array}{l}\text { Mito } \\
\text { Cov. }\end{array}$ & $\begin{array}{r}\text { Plastid } \\
\text { Cov. }\end{array}$ & $\begin{array}{r}\text { Mito } \\
\text { per } \\
\text { Nuclear }\end{array}$ & $\begin{array}{r}\text { Plastid } \\
\text { per } \\
\text { Nuclear }\end{array}$ \\
\hline Silene latifolia & $7.58 \mathrm{E}+10$ & $3.53 \mathrm{E}+08$ & $1.68 \mathrm{E}+09$ & $2.67 \mathrm{E}+09$ & $2.53 \mathrm{E}+05$ & $1.52 \mathrm{E}+05$ & 29.22 & 1394.70 & 11047.66 & 47.72 & 378.02 \\
\hline Silene noctiflora & $1.41 \mathrm{E}+11$ & $3.45 \mathrm{E}+09$ & $2.10 \mathrm{E}+09$ & $2.78 \mathrm{E}+09$ & $6.73 E+06$ & $1.52 \mathrm{E}+05$ & 52.70 & 512.25 & 13838.01 & 9.72 & 262.59 \\
\hline Silene conica & $1.20 \mathrm{E}+11$ & $5.95 \mathrm{E}+08$ & $5.51 \mathrm{E}+09$ & $9.30 \mathrm{E}+08$ & $1.13 \mathrm{E}+07$ & $1.47 \mathrm{E}+05$ & 136.49 & 52.55 & 37486.69 & 0.38 & 274.64 \\
\hline
\end{tabular}


Table S6. ddPCR droplet counts and copy number calculations

\begin{tabular}{lllrrrrr}
\hline Sample & Genome & Marker & $\begin{array}{r}\text { Positive } \\
\text { droplets }\end{array}$ & $\begin{array}{l}\text { Negative } \\
\text { droplets }\end{array}$ & $\begin{array}{l}\text { Copies per } \\
\text { reaction }\end{array}$ & $\begin{array}{l}\text { Dilution } \\
\text { Factor }\end{array}$ & $\begin{array}{l}\text { Copies per } \\
\text { nuclear copy }\end{array}$ \\
\hline New1 & Mito & matR & 1244 & 6955 & 3967 & 1 & 0.98 \\
New2 & Mito & matR & 2413 & 10431 & 4900 & 1 & 1.09 \\
New3 & Mito & matR & 1987 & 11250 & 3820 & 1 & 0.91 \\
Original & Mito & matR & 2356 & 13893 & 3680 & 1 & 0.42 \\
New1 & Mito & nad9 & 1842 & 10249 & 3880 & 1 & 0.96 \\
New2 & Mito & nad9 & 1202 & 4781 & 5280 & 1 & 1.18 \\
New3 & Mito & nad9 & 990 & 5106 & 4160 & 1 & 1.00 \\
Original & Mito & nad9 & 2268 & 13951 & 3540 & 1 & 0.41 \\
New1 & Plastid & petA & 6502 & 7514 & 14660 & 200 & 727.54 \\
New2 & Plastid & petA & 6692 & 6199 & 17220 & 200 & 767.04 \\
New3 & Plastid & petA & 6392 & 8264 & 13480 & 200 & 644.98 \\
Original & Plastid & petA & 5601 & 1651 & 34820 & 200 & 804.16 \\
New1 & Plastid & rpoB & 5868 & 6456 & 15220 & 200 & 755.33 \\
New2 & Plastid & rpoB & 6803 & 6015 & 17800 & 200 & 792.87 \\
New3 & Plastid & rpoB & 6409 & 8078 & 13740 & 200 & 657.42 \\
Original & Plastid & rpoB & 10798 & 4448 & 28980 & 200 & 669.28 \\
New1 & Nuclear & AT1G06040 & 1524 & 7912 & 4140 & 1 & 1 \\
New2 & Nuclear & AT1G06040 & 1751 & 8889 & 4240 & 1 & 1 \\
New3 & Nuclear & AT1G06040 & 2070 & 10630 & 4180 & 1 & 1 \\
Original & Nuclear & AT1G06040 & 3982 & 10165 & 7780 & 1 & \\
New1 & Nuclear & AT1G07630 & 1756 & 9820 & 3920 & 1 & \\
New2 & Nuclear & AT1G07630 & 2242 & 10039 & 4740 & 1 & \\
New3 & Nuclear & AT1G07630 & 2118 & 10890 & 4180 & 1 & \\
Original & Nuclear & AT1G07630 & 5315 & 10629 & 9540 & & 1 \\
\hline
\end{tabular}


bioRxiv preprint doi: https://doi.org/10.1101/2020.12.09.418582; this version posted February 11, 2021. The copyright holder for this preprint (which was not certified by peer review) is the author/funder, who has granted bioRxiv a license to display the preprint in perpetuity. It is made available under aCC-BY-NC 4.0 International license.

Table S7. Detection of mitochondrial SNVs in multiple biological replicates

\begin{tabular}{llrrrrrrr}
\hline Species & SNV Detection & A $>$ C & A $>\mathbf{G}$ & A $>\mathbf{T}$ & $\mathbf{C}>\mathbf{A}$ & $\mathbf{C}>\mathbf{G}$ & $\mathbf{C}>\mathbf{T}$ & Total \\
\hline Silene conica & Shared among replicates & 17 & 100 & 5 & 3 & 1 & 2 & 128 \\
Silene conica & Unique to one replicate & 32 & 157 & 28 & 19 & 19 & 21 & 276 \\
Silene latifolia & Shared among replicates* & 0 & 0 & 0 & 0 & 0 & 0 & 0 \\
Silene latifolia & Unique to one replicate & 3 & 3 & 7 & 7 & 5 & 33 & 58 \\
Silene noctiflora & Shared among replicates & 0 & 0 & 0 & 0 & 0 & 0 & 0 \\
Silene noctiflora & Unique to one replicate & 6 & 20 & 1 & 2 & 15 & 14 & 58 \\
\hline
\end{tabular}

${ }^{* \star}$ The use of parentals for $k$-mer filtering may have biased against detection of shared SNVs in S. latifolia (see main text). 